\title{
The problem of spatial fit in social-ecological systems: detecting mismatches between ecological connectivity and land management in an urban region
}

\author{
Arvid Bergsten $^{1}$, Diego Galafassi ${ }^{1}$ and Örjan Bodin $^{1}$
}

\begin{abstract}
The problem of institutional fit in social-ecological systems has been empirically documented and conceptually discussed for decades, yet there is a shortage of approaches to systematically and quantitatively examine the level of fit. We address this gap, focusing on spatial fit in an urban and peri-urban regional landscape. Such landscapes typically exhibit significant fragmentation of remnant habitats, which can limit critical species dispersal. This may have detrimental effects on species persistence and ecosystem functioning if land use is planned without consideration of the spatial patterns of fragmentation. Managing habitat fragmentation is particularly challenging when the scale of fragmentation reaches beyond the control of single managers, thereby requiring different actors to coordinate their activities to address the problem at the appropriate scale. We present a research approach that maps patterns of collaborations between actors who manage different parts of a landscape, and then relates these patterns to structures of ecological connectivity. We applied our approach to evaluate the fit between a collaborative wetland management network comprising all 26 municipalities in the Stockholm County in Sweden and an ecologically defined network of dispersed but ecologically interconnected wetlands. Many wetlands in this landscape are either intersected by the boundary between two or more municipalities, or are located close to such boundaries, which implies a degree of ecological interconnectedness and a need for intermunicipal coordination related to wetland management across boundaries. We first estimated the level of ecological connectivity between wetlands in neighboring municipalities, and then used this estimate to elaborate the level of social-ecological fit vis-à-vis intermunicipal collaboration. We found that the level of fit was generally weak. Also, we identified critical misalignments of ecological connectivity and intermunicipal collaboration, respectively, as well as collaborations that represented an adequate alignment. These findings inform on where to most effectively allocate limited resources of collaborative capacity to enhance the level of social-ecological fit. Our approach and results are illustrated using maps, which facilitates the potential application of this method in land use planning practice.
\end{abstract}

Key Words: connectivity; graph theory; institutional fit; landscape; network; planning; scale mismatch; spatial mismatch; Stockholm; urban; wetland

\section{INTRODUCTION}

The problem of fit in social-ecological systems has been documented and discussed for decades and shown to constrain the integration of conservation and development goals (Folke et al. 1998, 2007, Young 2002, Brown 2003, Berkes 2006, Cumming et al. 2006, Borowski et al. 2008, Brondizio et al. 2009, Guerrero et al. 2013). Dimensions of fit under discussion include geographical, jurisdictional, or functional fit (Cumming et al. 2006), of which most papers refer to simply as the problem of institutional fit. In spite of this broad interest, there is still a shortage of approaches to quantify the level of social and ecological fit and to localize mismatches in an integrated way. In fact, Pelosi et al. (2010) reviewed the literature on spatial mismatches in agriculture and found that only $15 \%$ of the papers explicitly considered both ecological and social processes in the system. The remaining $85 \%$ investigated either social or ecological processes, even though they all talked about social-ecological scale mismatches.

Still, there have been some promising attempts. Ekstrom and Young (2009) developed an approach that measures the functional fit between a part of an ecosystem and a set of institutions. Another transdisciplinary model for evaluating social-ecological fit was presented by Bodin and Tengö (2012) and extended by Bodin et al. (2014). We continue this development and concentrate on institutional fit related to the spatial matching of ecological and governance processes by looking at a regional urban/peri-urban landscape in central Sweden. Spatial mismatches occur when an ecological process cannot be managed adequately, either because management actions are applied at a coarser or finer scale than is relevant to solve the ecological problem (resolution mismatch) or because ecological processes transcend governance boundaries (boundary mismatch) (Cumming et al. 2006). These types of mismatches can overlap, for example, in cases where jurisdictional boundaries force actors to manage ecological processes at too fine scales. Boundary mismatches are impossible to resolve if the focal ecological processes are not contained within the spatial jurisdiction of either a single high-level actor responsible for the whole area or by several lower level actors who collaborate and thus together constitute a coherent governance system at the larger scale (Pelosi et al. 2010, Termeer et al. 2010). We focus on the latter case, in which the degree of spatial fit depends on the collaboration between actors, each governing only a part of the larger area defined by the focal ecological processes.

It has been argued that spatial mismatches are generally more pronounced in urban landscapes than other social-ecological systems (Borgström et al. 2006, Ernstson et al. 2010). The intensive, patchy, and changing land use in urbanized regions poses a fundamental challenge to planners, who need to carefully evaluate the effects of new development plans in order to maintain ecological connectivity (Niemelä 2011). Urbanization also generally means smaller and more isolated fragments of habitat for most species. Taken together, this implies an elevated risk of local extinction, since long-term species persistence depends on 
the connectivity to other habitat areas from where recolonization could occur (Hanski 1999, Fahrig 2003, Bergsten et al. 2013). On top of this, many urban regions comprise a multitude of administrative subdivisions, which further complicates the management of ecological dynamics in terms of avoiding boundary mismatches (Pickett et al. 1997, 2001).

This study covers all the 26 municipalities of Stockholm County, which hosts a growing population of 2.1 million inhabitants. Half the population lives in the central Stockholm Municipality, and the remaining half is distributed in the remaining municipalities, which have varying degrees of urbanization. We concentrate on wetland ecosystems and, in particular, species dispersal processes that connect wetlands that are up to $5 \mathrm{~km}$ apart, thereby influencing diversity of species and ecosystem services at the scale of individual wetlands as well as at the county scale. Urban wetlands are local biodiversity hot spots, and their rarity implies an elevated importance as providers of ecosystem services and wildlife habitat (Baldwin 2011). Since 1900, more than half of the world's wetland area has been lost (Zedler and Kercher 2005). The effect of wetland loss on regional biodiversity may be much larger than what would be expected from the mere loss of habitat area (Amezaga et al. 2002, Baldwin 2011). In fact, previous research has attributed the failures of wetland protection policies to the complexity and "invisibility" of spatial relationships among wetland water and vegetation (Turner et al. 2000).

The ecological integrity of wetlands relies on viable species populations, which in turn rely on the ability to disperse between wetlands. The potential for dispersal is affected both positively and negatively by different human activities. The key governance domains in our study case are land use planning and urban development, and in particular, more direct wetland management, like habitat preservation and draining for forestry and agriculture. Swedish legislation states that land use planning is generally a responsibility of municipal governments (the Swedish "municipal planning monopoly"; Plan and Building Act) (Sweden 2010). Compared to governance systems in other metropolitan regions in Europe, the regional actors in Stockholm County have only indicative and advisory powers, leaving municipalities as the only strong type of player (Emmelin and Lerman 2006, Schmitt 2010). Regional authorities may exert some indirect influence on municipal planning outcomes; e.g., through regional scenario planning, directives, and information. Although their wider spatial focus may address spatial mismatches, the municipal planning monopoly often prevents regional actors from progressing beyond a role as advisories or facilitators (unless a municipality is breaking formal regulations). The regulatory emphasis on municipalities as base units for land use planning and nature management thus favors governance of locally contained ecological processes, in contrast to ecological processes that transcend municipal boundaries (Fig. 1). It means that most of the decision-making power on land use is distributed and decentralized, which adheres to some basic principles of polycentric governance. Without further discussing whether the decision-making power should preferably be locally or regionally based, the current institutional and legal framework in the study area suggests that intermunicipal collaboration may take an important role in addressing boundary (and resolution) mismatches. Mismatches can then be avoided by a joint management of shared wetlands and wetland connections, or at least by communicating intentions and activities to neighboring municipalities. From the perspective of a local government, there are compelling reasons to engage more in wetland-related collaboration with an adjacent actor with whom it is ecologically connected to, than with a neighbor with whom it is not connected. These collaborations may have positive outcomes on the local functioning of wetlands as well as on higher level functions of the county-wide wetland system. There are indeed a few documented examples of formalized multimunicipal collaborations regarding planning, green infrastructure, and water quality (e.g., Stephan et al. 2006, TMR 2010, 2013). However, these projects have not specifically targeted the biodiversity and functions of wetlands, and they have not addressed nonaquatic biotic processes. Collaboration between municipalities may therefore play an important role in maintaining nonaquatic wetland connectivity.

Fig. 1. We focus on social-ecological mismatches across municipal boundaries. In this illustration, four municipalities share a pattern of ecological connectivity (green nodes and links) that does not fully fit the pattern of collaborations (boxes and red links). More specifically, Municipality B shares an ecological link but no collaborative link with $\mathrm{C}$, whereas it has a collaborative tie but no wetland connectivity with Municipality D. The illustration also demonstrates how we conceptualize the possibilities for bridging these mismatches. Intermunicipal collaborations are the main conduit through which individual land use planning instruments can be set into communication. One of the main activities of regional actors and regional planning is to provide platforms where such collaboration can emerge.
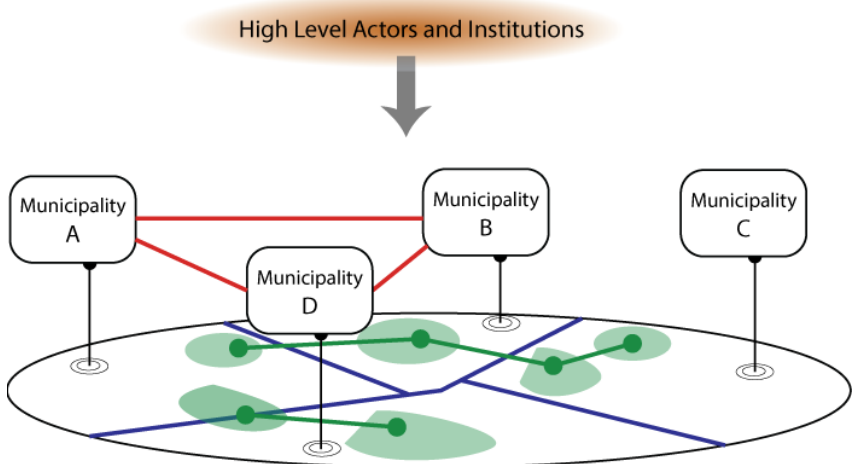

Our purpose is threefold. First, by combining spatially explicit representations of both social and ecological systems using a network modeling approach, we develop a simple but generic cross-disciplinary method to assess the extent of spatial fit (alignment) of ecological processes and governance systems, as seen through the lens of collaboration between autonomous but neighboring land managers (municipalities in this study) (see also Treml et al. 2013).

Secondly, we apply this approach to investigate the level of socialecological fit in our study system in Stockholm County, Sweden. We concentrate on collaboration patterns among municipal governments and ecological patterns of nonaquatic connectivity among all the 641 wetlands in the study area. Previous research 
and policy work in the region have suggested that municipalities are becoming increasingly aware of cross-municipal ecological connections that affect the local ecology (Stockholm Municipality 2007, Bergsten and Zetterberg 2013). Most notably, the concept of regional green infrastructure has been broadly communicated to the municipalities by county authorities (TMR 2010). This triggered us to test whether bilateral collaborations are more common between neighboring municipalities than between nonadjacent municipalities (hypothesis $\mathrm{H}_{\mathrm{nbr}}$ ). We then test whether collaborations are correlated with critical wetland connectivity $\left(\mathrm{H}_{\mathrm{fit}}\right)$. If true, $\mathrm{H}_{\mathrm{fit}}$ implies a tendency towards addressing social-ecological boundary mismatches for wetland governance in particular, whereas $\mathrm{H}_{\text {nbr }}$ suggests that municipalities choose their wetland collaboration partners in such a way that it enhances bilateral social-ecological fit in general, but does not adapt particularly to wetland connectivity. A lack of positive outcomes on both $\mathrm{H}_{\mathrm{nbr}}$ and $\mathrm{H}_{\text {fit }}$ would indicate an absence of effective mechanisms that operate toward increasing the level of fit between cross-boundary ecological processes in general (rejection of $\mathrm{H}_{\mathrm{nbr}}$ ) and wetland-oriented processes in particular (rejection of $\mathrm{H}_{\text {fit }}$ ) vis-à-vis the pattern of collaborative wetland management.

Thirdly, we identify and locate critical connections in the socialecological landscape that deserve special attention. Using maps, we display such mismatches and matches between bordering municipalities:

1. neighboring municipalities that should continue their collaboration because of high wetland connectivity (match)

2. neighboring municipalities that may relocate coordination resources because of low wetland connectivity, or alternatively, that may use the existing collaboration to initiate a wetland restoration project (ambiguous mismatch)

3. neighboring municipalities that should increase coordination to protect a high wetland connectivity (mismatch)

The third and last aim thus changes the scope from assessing the overall level of spatial fit to instead identifying critical municipal boundaries. This involves localizing gaps where deliberate attempts to enhance the level of fit would be most effective, either by establishing new collaborative ties or by creating/restoring wetland areas. This third aim also includes an attempt to expand the geographical scale and analyze how regional wetland structures and aggregations stretch over multiple municipalities and not just specific municipal boundaries. Are there regional connections implying that some municipalities are more important than others when it comes to protecting wetland connectivity on the county-wide scale?

\section{METHODS}

\section{Study site}

Wetlands are a conservation priority in most societies because of the number of species and ecosystem services associated with them, and because of the sheer amount of areal losses due to human activities (Haig et al. 1998, Zedler and Kercher 2005, Costanza et al. 2006, ten Brink et al. 2012). Sweden has the second largest wetland area in Europe $\left(90,000 \mathrm{~km}^{2}\right)$ and Europe's largest variation in wetland types (Gunnarsson and Löfroth 2009).
Important wetland services in Sweden include pasture, nutrient retention, water purification, pollination, carbon sequestration, bird-watching, and hunting (SEPA 2012).

Landscape change around the world has reduced the populations of many wetland plants and animals. The population viability of a wetland species is affected through habitat loss and fragmentation; i.e., by impinging on the ability of organisms to move between wetlands. Studies on urban wetlands have found negative correlations between plant diversity and distances between wetlands (Lopez and Fennessey 2002, Lopez et al. 2002, Cohen et al. 2004, Matthews et al. 2005, Reiss 2006). Globally, $41 \%$ of the world's amphibian species are now threatened (Frost 2013), and their interaction with the landscape makes them sensitive to fragmentation (Sjögren 1991, Joly et al. 2001, Marsh and Trenham 2001). The largest potential to halt the decline in amphibian species comes from landscape-scale conservation plans that manage connectivity patterns (Cushman 2006).

In Stockholm County, $90 \%$ of the current wetland area has been affected by peat mining and draining for farming and forestry (SCAB 2013). Urban development and road construction are currently the main threats to the county's wetlands and their connectivity. However, there is a possibility of compensation thanks to a current political interest to protect and even restore wetlands (SCAB 2013). New national legislation in the 1990s impeded the construction of new ditches, but this measure was counterbalanced by intensified clearing of old ditches (Tranvik and Bjekle 2010). The National Strategy for Thriving Wetlands (SEPA 2005) stipulates that measures for species conservation and for the restoration and protection of wetlands, which safeguard valuable wetlands and ecosystem functioning, shall be in place by 2020.

The 26 municipalities in the county differ greatly in size, with a mean land area of $251 \mathrm{~km}^{2}$ and $383 \mathrm{~km}^{2}$ in standard deviation (median size $=142 \mathrm{~km}^{2}$, county land area $=6526 \mathrm{~km}^{2}$ [Statistics Sweden 2013]). Urban planners in the county are challenged to accommodate an accelerating urbanization while simultaneously managing biodiversity and promoting a sensible use of nature. Lately we have seen more actions to protect and restore wetlands as a response to wetland degradation in the 20th century and to an increased awareness of wetland ecology.

\section{Analyzing spatial fit through network analysis}

Our approach to analyzing spatial fit requires that we define the social and ecological networks in terms of nodes and links (Fig. 1). In social network analysis, nodes usually represent people or organizations, and links represent relations between nodes, like communication patterns, collaborations, or resource exchange (Wasserman and Faust 1994, Scott 2000, Borgatti et al. 2009). Social network analysis has been applied to social-ecological systems to study how network structure and variation in connectivity influence network performance and the behavior of individual actors (Bodin and Prell 2011). Combining results from network analyses of social and ecological data can be a constructive way to elicit management implications about a social-ecological system (Bodin and Tengö 2012, Rathwell and Peterson 2012, Guerrero et al. 2013). In this study, social nodes represent municipalities, and social links represent intermunicipal collaboration ties concerning wetland management (Fig. 1). 
Spatial ecological networks have been used in landscape and movement ecology to represent resource patches as nodes, whereas links represent an ecological process that connects nodes, such as dispersal and exchange of energy or genetic material (Cantwell and Forman 1993, Urban and Keitt 2001, Bodin and Norberg 2007, Dale and Fortin 2010, Galpern et al. 2011). Ecological network analysis has been used to study metapopulations threatened by habitat fragmentation, for example, in urban regions where the level of connectivity between patches is often critically low and needs to be actively managed (Urban et al. 2009). Biodiversity and ecosystem service provision are thus influenced by the spatial organization of resource patches that constitute the habitats of species in a landscape. In this study, ecological nodes represent wetlands, and ecological links represent ecological connectivity through dispersal between wetlands. Our analysis of the fit between wetland management and wetland ecology builds on the assumption that wetland conservation planning and alternative land uses are controlled through the management processes of the local administration of the municipality in which the wetland is located, as represented in Fig. 1. Of course, this assumption has its exceptions-an interesting local case being the ponds maintained by golf course managers (Colding et al. 2009). Although some wetlands are privately owned, only the municipalities develop comprehensive spatial plans of larger areas. Also, municipalities have a central position in developing management guidelines, regulations, restoration incentives, and construction permits that potentially affect all the wetlands within their borders.

\section{Wetland data and connectivity assessment}

We used publicly available data on 641 wetlands with a mean area of 23.1 ha ( 22.8 ha in standard deviation), totaling $2 \%$ of the county's land area (Gunnarsson and Löfroth 2009; Appendix 1 shows the wetland distribution in the study area). The distances between wetlands limit the chance of dispersal success, which in turn affects the survival of a species and its ability to relocate and recolonize in response to habitat changes and local population dynamics (Bergsten et al. 2013, Saura et al. 2014). To accommodate a range of species with different dispersal capabilities, we applied 1, 2, 3, 4, and $5 \mathrm{~km}$ as interwetland threshold distances in our connectivity analyses. The range involves the maximum dispersal distances of several amphibian species that have been target species in wetland restoration projects and/or that have been used as indicators of biological diversity; for example, the common toad (Bufo bufo), the pool frog (Rana lessonae), the crested newt (Triturus cristatus), the firebellied toad (Bombina bombina), the natterjack toad (Epidalea calamita), and the tree frog (Hyla arborea). Appendix 2 describes the wetland data used, some relevant research on amphibians in ecological conservation and restoration, and the empirical estimates of dispersal distances that motivated the use of the 1$5 \mathrm{~km}$ range in our case study. The lower distance limit also relates to the review in Smith and Green (2005) of 53 amphibian species, where $44 \%$ of 102 references reported maximum dispersal distances of more than $1 \mathrm{~km}$. We stress that our method requires that the interwetland distance be carefully considered when mapping the ecological connections. The precision of networkbased connectivity models can be further enhanced by incorporating matrix data; i.e., of the land use between the patches of the focal resource, such as elevation data, the road network, or observed dispersal events (e.g., Zetterberg et al. 2010).

\section{Ecological network analysis}

\section{Modeling connectivity using a network approach}

Our ecological network analysis represents individual wetlands as nodes. Spatial network analysis has been applied in many conservation studies of wetland systems and spatially structured amphibian populations (e.g., Fortuna et al. 2006, Wright 2010, Zetterberg et al. 2010, Ribeiro et al. 2011, Peterman et al. 2013). Two nodes are directly connected by a link if the wetland edgeto-edge distance does not exceed the threshold distance $d$. Two wetlands ( $i$ and $j$ in Eq. 1 ) that belong to the same component are indirectly connected through a number $n l_{i j}$ of intermediate links. Fig. 2 displays a part of the wetland system for $d=2$ and $d=4 \mathrm{~km}$.

\section{Regional wetland structures}

Before analyzing the interaction of individual wetlands and municipal geographical boundaries, we performed a course-grain analysis of the distribution of wetlands in Stockholm County and areas with high wetland density. To do so, we converted the wetland vector data to a $25-\mathrm{m}$ resolution raster and created a first density map using a moving circle with a $2-\mathrm{km}$ radius. The same moving-circle algorithm was applied to the output, which produced the aggregations displayed in Fig. 3. Each aggregation represents a continuous area in which an organism is assumed to be able to reach and frequently utilize habitat resources when foraging and adjusting to seasonal variations (Ray et al. 2002). These aggregations show that a continuous area with high wetland density may extend over several municipalities, which supplements the analysis that focused on one municipal boundary at a time.

\section{Identifying critical ecological connections}

We estimated the contribution of each node (wetland) and each link to the global connectivity measure IIC (integral index of connectivity) (Pascual-Hortal and Saura 2006). IIC measures habitat availability in a landscape from a species perspective by accounting for the areas and spatial arrangement of habitat patches in a landscape - in this case, of the wetlands in the whole of Stockholm County. IIC is given by the following formula:

$$
I I C=\frac{1}{A_{L}^{2}} \sum_{i} \sum_{j} \frac{a_{i} a_{j}}{n l_{i j}+1}
$$

where $a_{i}$ and $a_{j}$ are the areas of wetland $i$ and $j ; n l_{i j}$ is the number of links in the shortest path between wetlands $i$ and $j$; and $A_{L}$ is the total study area. The IIC ranges from 0 , when there is no habitat, to 1, when habitat covers the entire landscape. For a given total habitat area in the landscape, IIC takes its highest value if the habitat is concentrated in one patch, and it takes its lowest value if the habitat is scattered in equally small and maximally isolated patches.

The importance of a wetland or wetland link is given by its dIIC value, which equals the percent decrease in IIC if this element is removed (Pascual-Hortal and Saura 2006). Hence, dIIC is a relative measure of a network element's contribution to the connectivity of the whole habitat network, and is a widely used indicator in conservation planning (Conefor 2014). The constant $A_{L}$ does not affect dIIC. A link has a high dIIC if it connects two nodes with large wetland areas (or significantly reduces $n l_{i j}$ ). The average link dIIC decreases with a larger dispersal-distance threshold $d$ since the total number of links in the network increases 
Fig. 2. The wetland network in a part of the study area, for $d=$ $2 \mathrm{~km}$ (a) and $d=4 \mathrm{~km}$ (b). Our fit analysis uses the sum of the dIIC values of all elements (wetlands and wetland links) crossed by each boundary between two municipalities. Two arrows point out a node and a link that have a potential strong influence on wetlands in two municipalities. These particular elements are also potential cross-scale bridges between a local wetland cluster and the regional structure of wetland zones shown in Fig. 3. The names of the municipalities are abbreviated as follows: DA $=$ Danderyd, $\mathrm{LI}=$ Lidingö, $\mathrm{SI}=$ Sigtuna, $\mathrm{SO}=$ Sollentuna, $\mathrm{SN}=$ Solna, $\mathrm{SU}=$ Sundbyberg, TÄ = Täby, UV = Upplands Väsby, VT = Vallentuna, $\mathrm{VH}=$ Vaxholm, ÖS = Österåker.
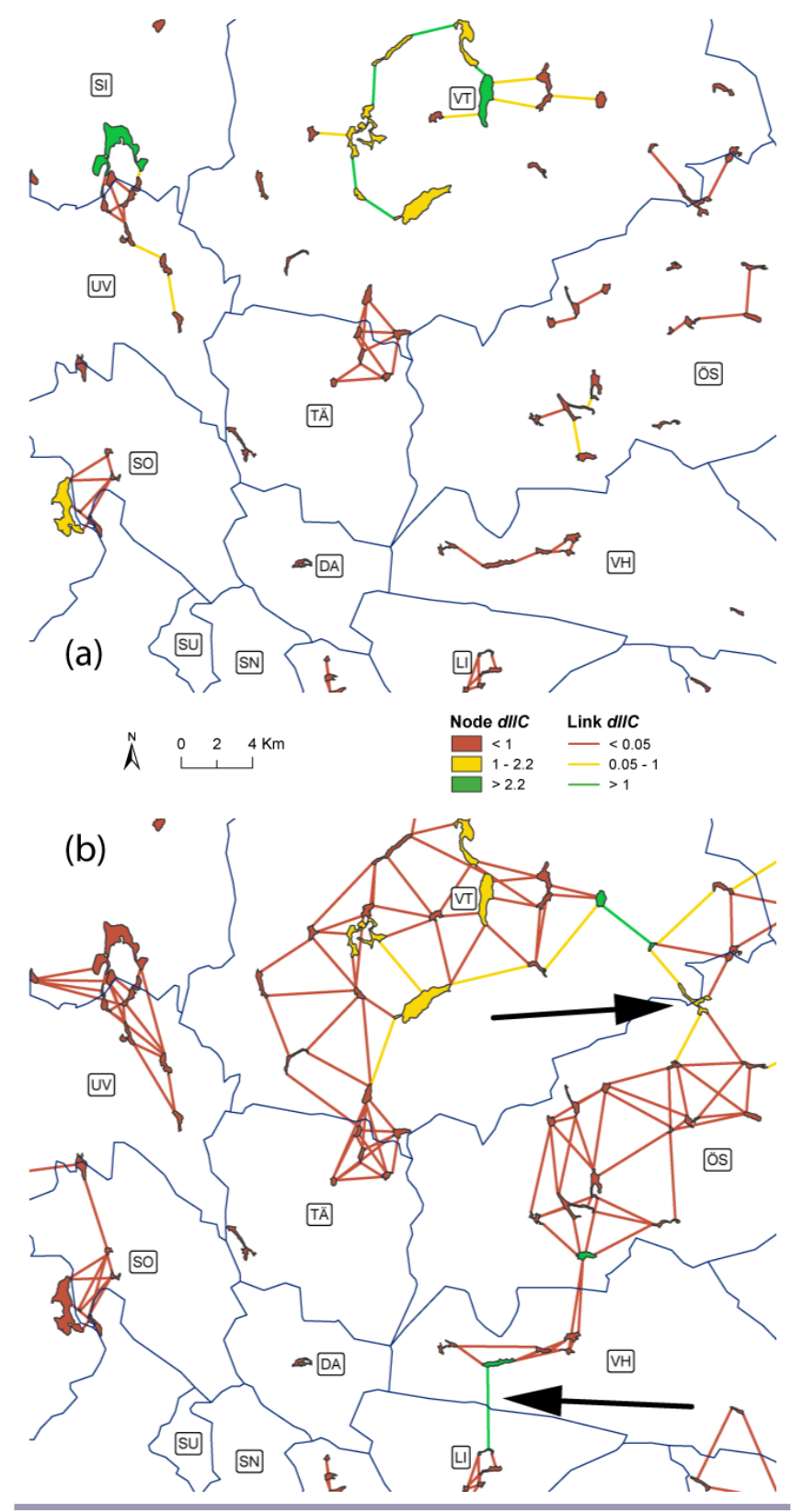

Fig. 3. Collaboration network and density-based wetlands aggregation. The names of the municipalities are abbreviated as follows: $\mathrm{BO}=$ Botkyrka, $\mathrm{DA}=$ Danderyd, $\mathrm{EK}=$ Ekerö, $\mathrm{HA}=$ Haninge, $\mathrm{HU}=$ Huddinge, $\mathrm{JÄ}=$ Järfälla, LI = Lidingö, NA = Nacka, NO = Norrtälje, NK = Nykvarn, NH = Nynäshamn, $\mathrm{SA}=$ Salem, $\mathrm{SI}=$ Sigtuna, $\mathrm{SO}=$ Sollentuna, $\mathrm{SN}=$ Solna, $\mathrm{ST}=$ Stockholm, SU = Sundbyberg, SÖ = Södertälje, TY = Tyresö, $\mathrm{TÄ}=$ Täby, UV = Upplands Väsby, UB = Upplands-Bro, VT = Vallentuna, VH = Vaxholm, VÖ = Värmdö, ÖS = Österåker.

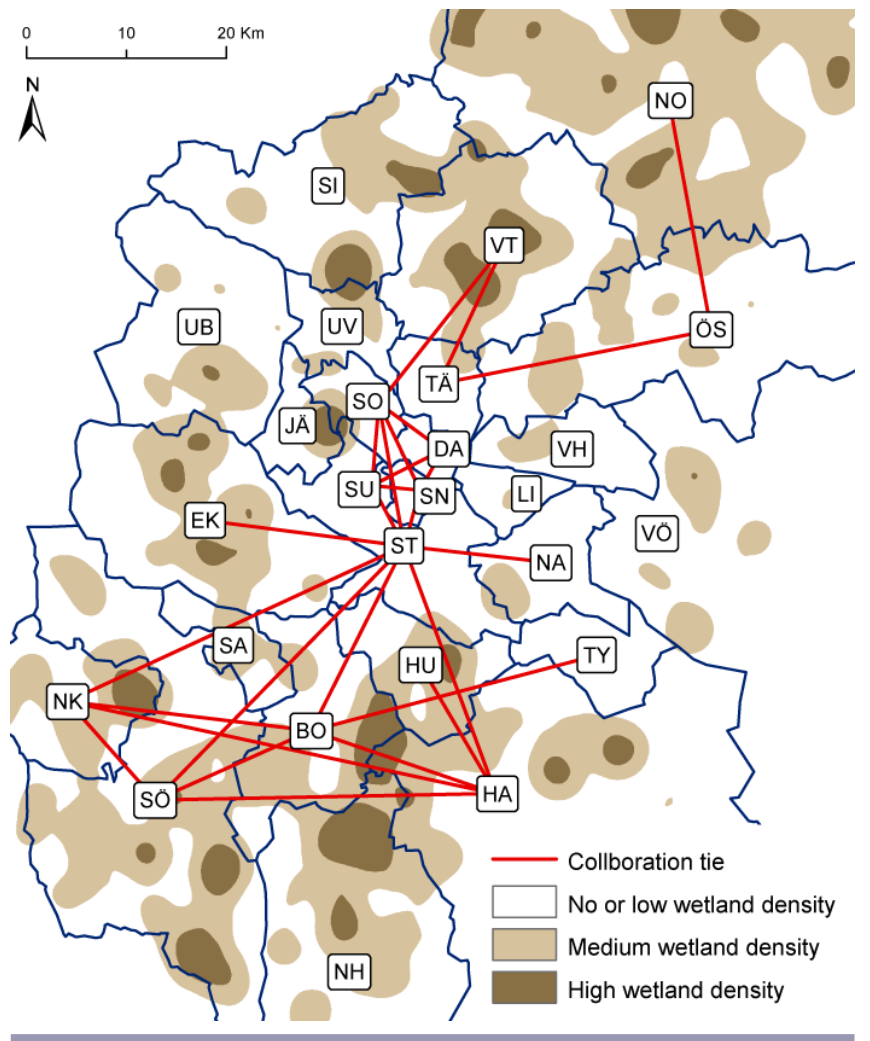

rapidly. A node contributes to IIC in the same way as links, and in addition, the dIIC of a node also increases with its wetland area. As a result, the dIIC value of a network element reflects how well it connects the wetland area available in a landscape. Ribeiro et al. (2011) found that dIIC values were unambiguously correlated with the amphibian diversity in a patch. From a conservation perspective, high connectivity values indicate locations that require attention when managing species whose populations are critically fragmented (Zetterberg et al. 2010, Ribeiro et al. 2011). In this study, we paid special attention to patches and links with high dIIC values that are also intersected by municipal borders, all of which implies a higher need for dialogue between these municipalities.

\section{Cross-boundary connectivity}

We estimated the ecological connectivity across municipal boundaries by summing the dIIC values of all elements $\left(e_{m}\right.$ in Eq. 2) that are crossed by the border between two municipalities. Thus, for each interwetland threshold distance (1-5 km), a bilateral ecological connectivity value was aggregated for each pair of neighboring municipalities. We then summed these pairwise 
values for all five distances analyzed in order to get a more comprehensive ecological network to compare with the collaboration data. Hence, the ecological connectivity (link weight) $E$ between municipalities $a$ and $b$ is given by the following formula:

$$
E_{a b}=\sum_{d} \sum_{m} d I I C\left(e_{m}\right)
$$

where $d$ is distances $0-5 \mathrm{~km}$ and $m$ is the number of elements that are intersected by a boundary at $d \mathrm{~km}$. To facilitate interpretation, we categorized the degree of summed cross-boundary connectivity into three levels: low connectivity (lower quartile), medium connectivity (interquartile range), and high connectivity (upper quartile) (see also Treml et al. 2013).

\section{Collaboration between municipalities}

The collaborative (social) network included municipalities as nodes and intermunicipal collaborations as links.

\section{Selection of respondents}

We surveyed municipal collaborations in 2011 by sending a webbased survey to municipal officials (mainly ecologists and environmental planners). All respondents were asked to reply to the survey on behalf of the municipal organization. The selection of respondents was based on the following criteria: respondents should work with spatial planning and management of natural resources, they participated directly or indirectly in decisionmaking to some degree (for example, by regularly providing ecological advice), and they were informed about collaborations with other municipalities. The last criterion was first estimated based on whether a potential respondent (to our knowledge) regularly participated in meetings where ecological issues of concern were discussed with officials from other municipalities. Secondly, we asked the respondents to forward the survey in case they had a colleague who was better informed than they were regarding the administration's collaboration with other municipalities. All respondents except two stated that they spent time ( $>0$ hours per month) on collaborations, thus confirming their relevance as respondents in this study. The two respondents who did not engage in collaboration stated that the municipality as a whole did not collaborate regarding green issues. Reminders (by email and/or phone) were given to potential respondents in several municipalities in order to collect answers from all municipalities in the study area. Most municipalities were represented by one respondent only (Appendix 3).

\section{The survey instrument}

Municipalities may have many types of collaborative efforts with other municipalities. For this study, we concentrated on collaborations related to wetland management. The survey presented a full list of all the 26 municipalities, and the respondent had to actively select either "no collaboration" or one of three predefined types of wetland-related collaborations: (1) information exchange; (2) coproduction of ecological knowledge, like reports and field assessments; or (3) policy work and joint planning and management (the survey instrument is presented in Appendix 4). We provided these alternatives to encourage the respondent to think about collaborations in a wide sense. Our social-ecological analysis assumed that these interaction types constitute opportunities to avoid boundary mismatches through increased awareness, collaborative reflection, or practical adaption vis-à-vis ecological processes.

\section{Collaboration data}

In the social network, we took into account only reciprocal links of any type $(n=54$, link density $=8.3 \%)$, which means that 50 links mentioned by only one of the two involved municipalities were left out in the Results section. This approach enhanced the fidelity of the collaboration network by reducing the risk of including very weak collaborative ties and limiting unintended effects of respondents' potential misinterpretations of the survey questions. Our analysis used the collaboration network only to assess its spatial fit with the ecological network. That is, no analysis of the social network alone was carried out since we focused on social-ecological matches (but see Appendix 3 for the node centrality of the municipalities in the collaboration network).

\section{Spatial comparison of social and ecological networks (fit analysis)}

Quadratic Assignment Procedure testing of fit hypotheses We used Multiple Regression Quadratic Assignment Procedure (MRQAP) (Dekker et al. 2007) to test if spatial adjacency and/or wetland cross-boundary ecological connectivity were able to predict the observed collaborations between municipalities (nodes). The MRQAP allows for a multivariate regression analysis where multiplex networks (i.e., adjacency matrices where the cells represent multiple links between nodes) are used to predict the configuration of another type of link in the network (the dependent variable). The MRQAP extends the simpler Quadratic Assignment Procedure (QAP) (Hanneman and Riddle (2005), which computes the correlation between the networks and tests the significance of association by developing standard errors with a random permutation method, and is thus a form of the widely used Mantel test (Mantel 1967, Legendre and Fortin 2010). We examined hypothesis $\mathrm{H}_{\mathrm{nbr}}$ using as an explanatory variable, the "neighbor network," in which a binary link represents a shared border between any given pair of nodes (i.e., representing whether the municipalities are neighbors or not). We examined hypothesis $\mathrm{H}_{\text {fit }}$ using as explanatory variable dIIC (ecological connectivity) between municipal nodes. QAP regression should be used with care for binary data (Robins et. al. 2012); thus, we complemented the regression analysis with pair-wise QAP correlation tests between the dependent variable (collaboration network) and the independent variables (neighbor network and ecological connectivity), respectively. MRQAP and QAP are implemented in Ucinet (Borgatti et al. 2002), and are described further by, for example, Hanneman and Riddle (2005).

\section{Bilateral matches}

We identified and localized social-ecological matches and mismatches by testing whether collaborations aligned with wetland connectivity for each pair of neighboring municipalities. We displayed the match or mismatch for each pair of municipalities where we found social and/or ecological connectivity, as represented in Fig. 4 (see also Treml et al. 2013).

\section{RESULTS}

\section{Collaborations and regional wetland zones}

The network of mutual collaborations was relatively sparse (Fig. 3). Of 26 actors, nine had no mutual collaborations, and eight had one or two ties (2.1 ties on average). Collaborative activities capable of improving the institutional fit included strategy development, conservation planning, water management, 
collection and sharing of field data, communication of planned developments or conservation actions, and restoration of wetland habitat.

Fig. 4. Types of social-ecological fit analyzed. Red represents mismatches with a high level of wetland connectivity but no collaboration. Purple denotes that wetland managers do communicate, although there is little or no wetland connectivity; we call these "ambiguous mismatches" since the collaboration might still be relevant to wetland connectivity of types other than those assessed in this study (e.g., through hydrology), or it may be instrumental to initiate a wetland restoration project. This color coding is used in Fig. 6 and Fig. 7.

\begin{tabular}{l|cc|c|} 
& & \multicolumn{2}{c}{ Collaboration } \\
& & Yes & No \\
\cline { 3 - 4 } $\begin{array}{l}\text { Wetland } \\
\text { connectivity }\end{array}$ & No & Ambiguous & Match \\
\cline { 3 - 4 } & Yes & Match & Mismatch \\
\cline { 3 - 4 } & &
\end{tabular}

There were two clusters of relatively well-connected municipalities: one in the southern part of the county, with quite large wetland areas, and another just north of Stockholm, whose municipalities have no or relatively little wetland area (Fig. 3). Coherent wetland aggregations or corridors of medium to high wetland density, in which one could expect that many wetlanddwelling species thrive, form on a regional scale (Fig. 3). An aggregation that stretches over several municipalities indicates that multimunicipal coordination is needed to adequately maintain connectivity on the regional scale, going beyond the issue of boundary mismatches between pairs of adjacent municipalities.

\section{Finding critical wetlands and wetland links}

Fig. 2 shows the connectivity between individual wetlands, assuming a maximum dispersal distance of $2 \mathrm{~km}$ and $4 \mathrm{~km}$. It illustrates how the spatial social-ecological complexity of wetland management increases when larger dispersal distances are considered. Many wetland clusters that are contained within the boundaries of a single municipality for $d=2 \mathrm{~km}$ are parts of larger boundary crossing clusters for $d=4 \mathrm{~km}$ (Fig. 2). In such cases, species with shorter maximum dispersal distance, like the crested newt or the common toad, do not disperse to or from adjacent municipalities, whereas, for example, the pool frog or the common shrew, which have longer dispersal distances, do interact with populations in adjacent municipalities (Appendix 2).

\section{Wetland connectivity between adjacent municipalities}

Fig. 5 shows the aggregated estimates of cross-boundary connectivity between adjacent municipalities (calculated using Eq. 2), illustrating that critical levels are found mostly at some distance from the county's center where the Stockholm Municipality (ST) is located. This reflects the lower density of wetlands and wetland links in the region's urban core (Fig. 3, Appendix 1). If there are no wetlands in a municipality, there cannot be cross-boundary connectivity.
Fig. 5. Cross-boundary ecological connectivity between adjoining municipalities, given by Eq. 2. Link color represents the summed dIIC for all links and nodes crossed by a specific municipal boundary. Absence of a link means that no wetland or wetland link up to $5 \mathrm{~km}$ is intersected by the boundary. Numbers represent a municipality's cross-boundary percentage of wetland connectivity. For example, cross-boundary elements equal $17 \%$ of all SI's nodes' and links' dIIC. The names of the municipalities are abbreviated as follows: $\mathrm{BO}=$ Botkyrka, $\mathrm{DA}=$ Danderyd, $\mathrm{EK}$ $=$ Ekerö, $\mathrm{HA}=$ Haninge, $\mathrm{HU}=$ Huddinge, $\mathrm{JÄ}=$ Järfälla, $\mathrm{LI}=$ Lidingö, $\mathrm{NA}=$ Nacka, $\mathrm{NO}=$ Norrtälje, $\mathrm{NK}=$ Nykvarn, $\mathrm{NH}=$ Nynäshamn, $\mathrm{SA}=$ Salem, $\mathrm{SI}=$ Sigtuna, $\mathrm{SO}=$ Sollentuna, $\mathrm{ST}=$ Stockholm, SÖ = Södertälje, TY = Tyresö, TÄ = Täby, UV = Upplands Väsby, UB = Upplands-Bro, VT = Vallentuna, $\mathrm{VH}=$ Vaxholm, VÖ = Värmdö, ÖS = Österåker.

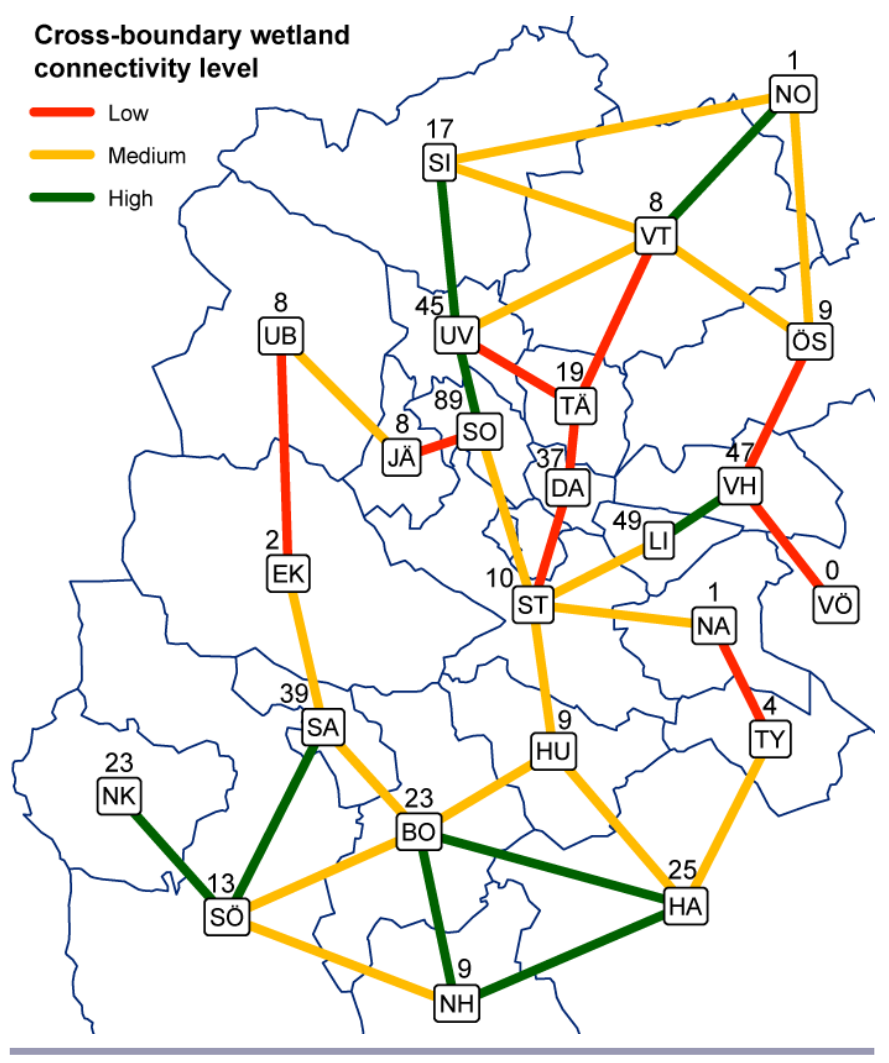

Localization of matches and mismatches

Of all collaborations found in the survey, $12 \%$ coincided with high connectivity, $29 \%$ with medium connectivity, $6 \%$ with low connectivity, and 53\% with no cross-boundary connectivity at all. The locations of the social-ecological matches and mismatches outlined in Fig. 4 are presented in Fig. 6 and Fig. 7. There were more spatial mismatches than matches, as expected given the relatively sparse collaboration network (Fig. 3). Nonetheless, seven of the boundaries with medium or high wetland connectivity were matched by collaboration ties (Fig. 6), thus adhering to what we defined as an adequate match. The red links in Fig. 7 mark the most negative type of boundary mismatch; i.e., a strong wetland connectivity but absence of a bilateral dialogue. 
Fig. 6. Collaborations matched to wetland connectivity (displaying only collaboration links between neighboring municipalities). A links represents wetland connectivity matched by collaboration. Link color represents the level of fit interpreted as the estimated importance of the collaboration tie when it comes to protecting wetland connectivity. For a green link, ending the collaboration has potentially severe impacts on wetland connectivity, whereas for a purple link, it would have little or no impact. The names of the municipalities are abbreviated as follows: $\mathrm{BO}=$ Botkyrka, $\mathrm{DA}=$ Danderyd, $\mathrm{EK}=$ Ekerö, HA = Haninge, $\mathrm{HU}=$ Huddinge, $\mathrm{JÄ}=$ Järfälla, LI = Lidingö, $\mathrm{NA}=$ Nacka, $\mathrm{NO}=$ Norrtälje, $\mathrm{NK}=$ Nykvarn, $\mathrm{NH}=$ Nynäshamn, SA = Salem, SI = Sigtuna, $\mathrm{SO}=$ Sollentuna, $\mathrm{SN}$ $=$ Solna, $\mathrm{ST}=$ Stockholm, $\mathrm{SU}=$ Sundbyberg, $\mathrm{SÖ}=$ Södertälje, $\mathrm{TY}=$ Tyresö, TÄ = Täby, UV = Upplands Väsby, UB = Upplands-Bro, VT = Vallentuna, VH = Vaxholm, VÖ = Värmdö, ÖS = Österåker.

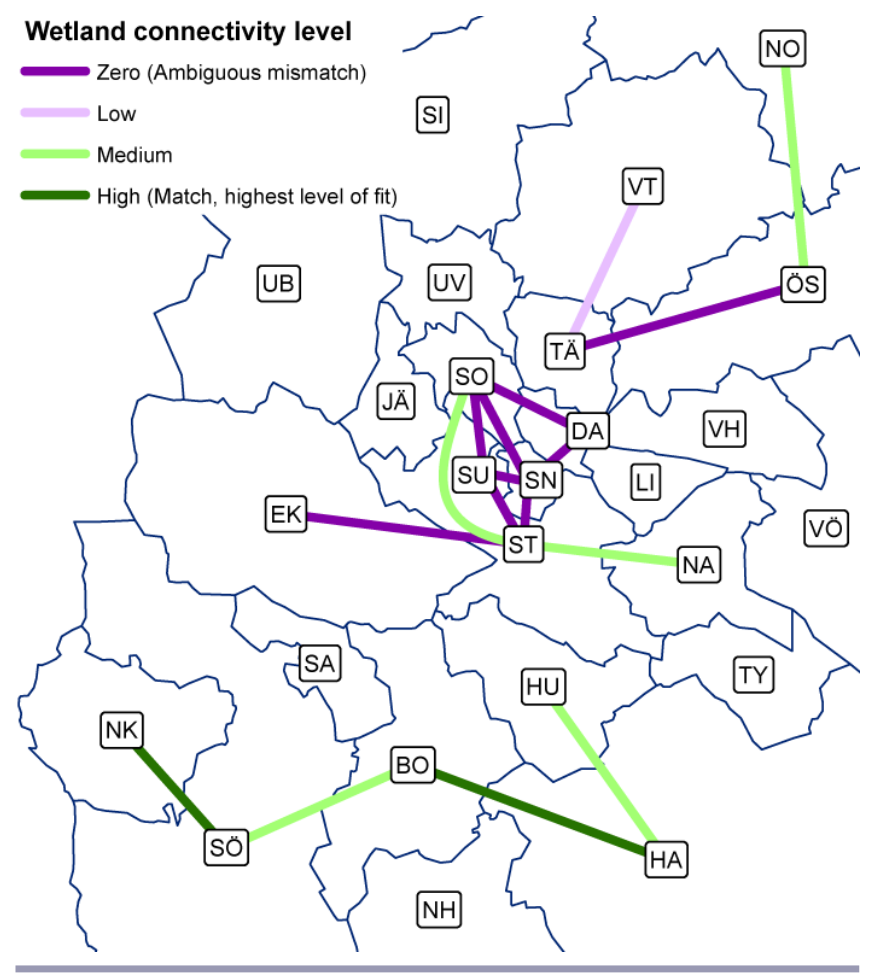

\section{The degree of social-ecological fit}

The bivariate regression model (MRQAP) was not able to predict collaboration particularly well, with an adjusted $R^{2}$ of $0.099(p=$ $0.001)$. However, the model showed the neighbor network was significantly correlated to the collaborative network (coefficient $=0.37, p=0.0005$ ), whereas the ecological network was not (coefficient $=-0.09, p=0.10$ ). The pair-wise QAP correlations (results not shown) showed the same pattern as the MRQAP analysis; i.e., that the neighbor network but not the ecological network was significantly correlated to the collaborative network. Hence, we found support for hypothesis $\mathrm{H}_{\text {nbr }}$ but not for $\mathrm{H}_{\text {fit }}$.
Fig. 7. A link represents wetland connectivity not matched by collaboration (that is, a link means that collaboration is absent). Link color represents the level of mismatch interpreted as the urgency of establishing a new collaboration to protect the corresponding level of wetland connectivity. The names of the municipalities are abbreviated as follows: $\mathrm{BO}=$ Botkyrka, DA $=$ Danderyd, $\mathrm{EK}=$ Ekerö, $\mathrm{HA}=$ Haninge, $\mathrm{HU}=$ Huddinge, $\mathrm{JÄ}$ $=$ Järfälla, $\mathrm{LI}=$ Lidingö, $\mathrm{NA}=$ Nacka, $\mathrm{NO}=$ Norrtälje, $\mathrm{NK}=$ Nykvarn, $\mathrm{NH}=$ Nynäshamn, $\mathrm{SA}=$ Salem, $\mathrm{SI}=$ Sigtuna, $\mathrm{SO}=$ Sollentuna, $\mathrm{SN}=$ Solna, $\mathrm{ST}=$ Stockholm, $\mathrm{SU}=$ Sundbyberg, SÖ = Södertälje, TY = Tyresö, TÄ = Täby, UV = Upplands Väsby, UB = Upplands-Bro, VT = Vallentuna, VH = Vaxholm, VÖ = Värmdö, ÖS = Österåker.

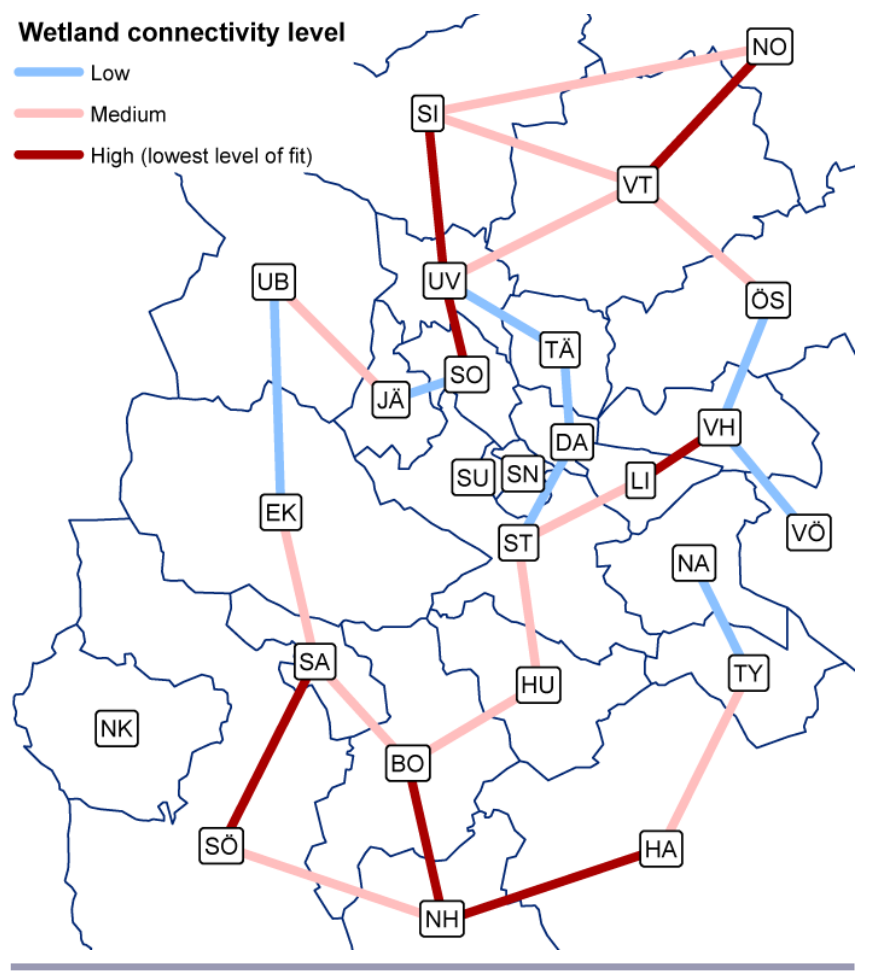

\section{DISCUSSION}

\section{Regional scale fit}

At the regional scale our analysis indicated regional corridors of medium to high wetland density that connect neighboring as well as non-neighboring municipalities (Fig. 3). For example, HA's wetlands are linked to SÖ and NK. Its collaborations with both direct neighbors and more remote municipalities enable HA to address wetland connectivity on both the regional scale (Fig. 3) and with specific neighbors (Fig. 5).

Our multiscale connectivity analysis suggests that the long distance dispersal between wetland aggregations in the county's northern and southern parts is rather limited. While wetland density (Fig. 3) indicated a potential regional corridor over UBEK-SA, the dIIC-based analysis (Fig. 5) revealed low wetland 
connectivity for EK-UB and JÄ-SO. Similarly, VH's connection to the small aggregations of wetlands in LI has the highest dIIC of all cross-boundary values in our analysis (Fig. 2b, Fig. 5). However, this connection continues southwards from LI over ST$\mathrm{HU}$ in a series of wetlands so few and fragmented that no continuous corridor is seen in the wetland area density map (Fig. 3, Fig. 5). From an institutional-fit perspective, it is serious that we found no collaboration ties along these two regional pathways. Instead, only ST has the position to enable a multimunicipal effort aiming to effectively manage connectivity between the county's southern and northern wetland systems.

This regional-scale analysis suggests that collaboration between two neighboring municipalities along a regional dispersal corridor has significance not only to the wetlands in the two municipalities. Rather, it may support the protection or enhancement of regional connectivity between wetland systems in the north and south of the county. Given that the whole region benefits from the conservation wetlands in LI, for example, we speculatively suggest that rather than relying on voluntary cooperation between municipalities, it is advisable that institutions at the regional level deal with connections that are regionally valuable. As called for by the European Water Framework Directive, multicounty institutions and some selforganized multimunicipality efforts to protect water quality have emerged in Sweden, based on delineated drainage basins. Although these are imperative measures, regional coordination should also consider nonaquatic ecological processes across watersheds (Amezaga et al. 2002, Soomers 2012), represented in this study by the density-based wetland zones (Fig. 3). Engaging actors in new governance initiatives is an expensive process, and the cost/benefit ratio can be reduced by considering the current patterns of collaborations and ecological connectivity. For example, an initiative concerning wetland systems in the whole of Stockholm County should make sure to involve the socially central actor ST, but also actors like LI and EK because they hold potential critical positions in the regional ecological network in combination with a latitudinal isolation in the collaborative network. In contrast, excluding these municipalities would reinforce the present regional social-ecological mismatches (Fig. 7).

\section{Cross-boundary fit}

Our results show that the surveyed municipalities have engaged in collaborations with each other, thereby actively increasing the level of fit. Yet, the sparse collaborations result in a high number of bilateral mismatches (Fig. 7). Since $53 \%$ of the present wetlandrelated collaborations are not matched with wetland connectivity, it seems that the social and ecological processes in our analysis are not matched in an efficient way. The statistical test of the level of alignment between the collaborative and the ecological networks further strengthens this conclusion, although the relatively weak tendency to collaborate more with neighboring municipalities does contribute to a better overall fit. Still, it is possible that the present collaborations may be instrumental in matching wetland connectivity that our particular case study does not take into account, such as hydrology or species dispersal at longer distances.

Strong wetland connectivity marks the need for a bilateral dialogue to coordinate management actions at the respective sides of the municipal boundary. It may prompt administrations to relocate resources spent on collaborating with other municipalities. For example, our results suggest that wetland managers in SO may consider increasing the collaboration with UV (Fig. 7). Other pairs of municipalities where the need for increased collaboration seem particularly pressing are UV and SI, VT and NO, LI and VH, BO and NH, NH and HA, and SÖ and SA. Note that some of these bilateral mismatches overlap with the gaps revealed in the regional analysis (Fig. 3).

We also found that some collaborations are maintained between municipalities that do not share any type of wetland connectivity (e.g., TÄ and ÖS in Fig. 6). This could be interpreted as an inefficient allocation of limited collaboration resources. Alternatively, one may choose to see such concurrence of weak ecological connectivity and already established collaboration as a leverage point for the restoration of wetland and crossboundary connectivity. In that perspective, the cluster of SO, SU, $\mathrm{SN}, \mathrm{DA}$, and ST has good prospect of joint construction or restoration of wetlands. These actors constitute an informal urban planning group called " $4 \mathrm{~S}+\mathrm{J}$ " (including JÄ but not DA) (Ingo et al. 2006). Furthermore, the eight southernmost municipalities constitute the Södertörn group in which municipalities engage jointly in, for example, infrastructure projects and nature conservation (Ingo et al. 2006). It is possible that these two groups - although not engaged primarily in wetland management-are the drivers behind the two compartments (clusters) of socially well-connected municipalities observable in Fig. 3. ST has the highest centrality with eight links, which is likely an effect of having half of the inhabitants of the study area and more resources to use on collaboration. These three examples of a possible "bias" towards having partners in wetland management are possible explanations for why we did not find support for hypothesis $\mathrm{H}_{\text {fit }}$; i.e., that municipalities tend to collaborate if their wetlands are connected. To find out exactly why two municipalities collaborate in wetland management, one would need to search in historical, cultural, economic, and institutional dimensions for factors not directly related to wetland connectivity. An approach to investigate institutional fit different from ours could be to map the multimunicipal collaboration groups that exist in the study area, and then investigate what spatial ecosystem structures these groups are capable of perceiving and managing.

\section{Improving the fit}

Empirical research in the Stockholm region has shown that the most pronounced spatial mismatches exist on the multimunicipal scale (Borgström et al. 2006, Ernstson et al. 2010). With this work, we hope to provide conceptual understanding and a practical approach for identifying such mismatches. A key property of our study system is the geographical separation of planning jurisdictions, known as the municipal "planning monopoly" in Sweden. As a consequence, our results show that spatial mismatches in relation to wetland governance exist, but the results also suggest that these mismatches may be resolved by means of multimunicipal cooperation. In the monocentric governance tradition, such arrangements are regarded to obscure the separate responsibilities of each autonomous municipality (Termeer et al. 2010). The multilevel governance tradition, on the other hand, emphasizes the role of coordination across governance levels (Hooghe and Marks 2003). The latter allows spatial mismatches 
to be probed and possibly resolved through complementarity activities between local actors who manage individual resources and regional actors who monitor ecological patterns at larger scales and coordinate management actions of local actors. In our web survey, all municipalities reported at least one interaction with an actor at a regional or municipal level (not shown). Still, it is clear that the municipalities in this case have not yet developed sufficient collaboration arrangements with other municipalities apt to adaptively govern the wetland patterns observed (Folke et al. 2005, Olsson et al. 2007), and will thus rely to a large extent on regional agencies for addressing boundary mismatches. In our study system, that issue is addressed to some degree by the county agency "Regional Growth, Environment and Planning (TMR)," which makes policy on green infrastructure management and hosts open discussions on planning and ecology. However, it is important to acknowledge that regional initiatives are more likely to succeed and guidelines are easier to implement if collaborative ties are already in place between municipalities.

To provide effective incentives for collaborative multimunicipal landscape management, Sweden's strongly decentralized planning likely needs to be legislatively supplemented with crosslevel governance mechanisms that more effectively than today accommodate cross-boundary ecological patterns (Bergsten and Zetterberg 2013). In addition, spatial matching is strengthened when land managers posses individual capabilities to experimentally understand and map spatial ecological patterns (Borowski et al. 2008, Bergsten and Zetterberg 2013, Cumming et al. 2013).

\section{CONCLUSION}

Our analytical approach recognizes that administrative boundaries are ecologically important, as they condition the scale and intensity of management activities that, in turn, affect ecosystem functions that often transcend the very same administrative boundaries. In contrast, traditional wetland conservation approaches are often based on the preservation of isolated sites considered to be of special importance, often due to their significance for migratory water birds (Amezaga et al. 2002). However, the neglect of spatial dependencies likely leads to socialecological mismatches, which over time may feed back detrimental consequences on the local wetlands.

However, the resolving of social-ecological mismatches requires analytical approaches that are social-ecologically integrative and capable of pointing out specific mismatches. Our paper proceeds along this path by providing a new way to localize potential spatial mismatches that necessitate indepth investigation of the social and ecological processes that are at work across a specific boundary (see also Treml et al. 2013). The method only requires that managers and resources are spatially associated; i.e., that actors interact with different parts of the landscape (overlapping or not). Social and ecological processes typically interact across scales in human-dominated ecosystems, and landscape planning needs to recognize patterns at the corresponding scales. The scales most easily observed are not necessarily meaningful for the ecological issue in focus. For example, readily observable data like species surveys or land cover maps are often relevant only when they enable the recognition of ecosystem functions at higher levels (cf. the multiscale model by Steinhardt and Volk 2003, and the resolution mismatches defined by Cumming et al. 2006). In our study case, the connectivity patterns of individual wetlands influence properties at a higher level of ecological organization, like species distributions and ecosystem services at the county scale. At the patch scale, our ecological network analysis ranked the connectivity contribution of individual wetland patches based on their size and spatial relation to all other wetlands in the landscape (Fig. 2). Assessing the connectivity of individual resource patches and safeguarding the ecological integrity of key areas are cost-effective measures to maintain desired properties at the ecosystem level. Studying the ecological network structure (Fig. 2) is also a feasible way to come up with locations where habitat restoration would enhance the connectivity of a whole wetland system.

Finally, network models of spatial ecological and social connectivity can easily incorporate more information about the nodes and the focal connecting processes. For example, attributes of social links can be used to represent the intensity of a relation, or to denote that two actors have an indirect relation through membership in the same cross-boundary organization (VanceBorland and Holley 2011). Ecological links can be weighted based on matrix quality; for example, how roads affect amphibian movement (Beaudry et al. 2008). Also, the social-ecological links between actors and resources can be further specified, for example, by differentiating types of management activities and ecosystem services, or by linking actors and resources across space (like when services and environmental impacts are transported to other locations) (Seitzinger et al. 2012). There is indeed a multitude of social and ecological connectivity patterns that relate to institutional fit. By modeling ecological and administrative patterns on the same scale so that they can be compared, our study demonstrates that it is possible to provide results of practical value to managers and policy-makers about how the spatial institutional fit can be understood and improved.

Responses to this article can be read online at: http://www.ecologyandsociety.org/issues/responses. php/6931

\section{Acknowledgments:}

Financial support was received from the Swedish Research Council Formas, from Mistra through a core grant to Stockholm Resilience Centre at Stockholm University, and from the Strategic Research Program EkoKlim at Stockholm University.

\section{LITERATURE CITED}

Amezaga, J. M., L. Santamaría, and A. J. Green. 2002. Biotic wetland connectivity - supporting a new approach for wetland policy. Acta Oecologica 23:213-222. http://dx.doi.org/10.1016/ S1146-609X(02)01152-9

Baldwin, A. H. 2011. Plant communities of urban wetlands: patterns and controlling processes. Pages 77-84 in J. Niemelä, J. H. Breuste, T. Elmqvist, G. Guntenspergen, P. James, and N. E. McIntyre, editors. Urban ecology: patterns, processes, and applications. Oxford University Press, USA. http://dx.doi. org/10.1093/acprof:oso/9780199563562.003.0010 
Beaudry, F., P. G. deMaynadier, and M. L. Hunter, Jr. 2008. Identifying road mortality threat at multiple spatial scales for semi-aquatic turtles. Biological Conservation 141(10):2550-2563. http://dx.doi.org/10.1016/j.biocon.2008.07.016

Bergsten, A., Ö. Bodin, and F. Ecke. 2013. Protected areas in a landscape dominated by logging - a connectivity analysis that integrates varying protection levels with competitioncolonization tradeoffs. Biological Conservation 160:279-288. http://dx.doi.org/10.1016/j.biocon.2013.01.016

Bergsten, A., and A. Zetterberg. 2013. To model the landscape as a network: a practitioner's perspective. Landscape and Urban Planning 119:35-43. http://dx.doi.org/10.1016/j.landurbplan.2013.06.009

Berkes, F. 2006. From community-based resource management to complex systems: the scale issue and marine commons. Ecology and Society 11(1):45. [online] URL: http://www.ecologyandsociety. org/vol11/iss1/art45/

Bodin, Ö., B. Crona, M. Thyresson, A-L. Golz, and M. Tengö. 2014. Conservation success as a function of good alignment of social and ecological structures and processes. Conservation Biology 28:1371-1379. http://dx.doi.org/10.1111/cobi.12306

Bodin, Ö., and J. Norberg. 2007. A network approach for analyzing spatially structured populations in fragmented landscape. Landscape Ecology 22:31-44. http://dx.doi.org/10.1007/ $\underline{\text { s10980-006-9015-0 }}$

Bodin, Ö., and C. Prell. 2011. Social networks and natural resource management: uncovering the social fabric of environmental governance. Cambridge University Press, Cambridge, UK. http://dx.doi.org/10.1017/CBO9780511894985

Bodin, Ö., and M. Tengö. 2012. Disentangling intangible socialecological systems. Global Environmental Change 22(2):430-439. http://dx.doi.org/10.1016/j.gloenvcha.2012.01.005

Borgatti, S. P., M. G. Everett, and L. C. Freeman. 2002. Ucinet for Windows: software for social network analysis. Analytic Technologies, Lexington, Kentucky, USA.

Borgatti, S., A. Mehra, D. Brass, and G. Labianca. 2009. Network analysis in the social sciences. Science 323:892-896.

Borgström, S., T. Elmquist, P. Angelstam, and C. AlfsenNorodom. 2006. Scale mismatches in management of urban landscapes. Ecology and Society 11(2):16. [online] URL: http:// www.ecologyandsociety.org/vol11/iss2/art16/

Borowski, I., J. P. Le Bourhis, C. Pahl-Wostl, and B. Barraqué. 2008. Spatial misfit in participatory river basin management: effects on social learning, a comparative analysis of German and French case studies. Ecology and Society 13(1):7. [online] URL: http://www.ecologyandsociety.org/vol13/iss1/art7/

Brondizio, E. S., E. Ostrom, and O. R. Young. 2009. Connectivity and the governance of multilevel social-ecological systems: the role of social capital. Annual Review of Environment and Resources 34(1):253-278. http://dx.doi.org/10.1146/annurev.environ.020708.100707

Brown, K. 2003. Integrating conservation and development: a case of institutional misfit. Frontiers in Ecology and the Environment 1:479-487. http://dx.doi.org/10.1890/1540-9295 (2003)001[0479:ICADAC]2.0.CO:2
Cantwell, M. D., and R. T. T. Forman. 1993. Landscape graphs: ecological modeling with graph theory to detect configurations common to diverse landscapes. Landscape Ecology 8(4):239-255. http://dx.doi.org/10.1007/BF00125131

Cohen, M. J., S. Carstenn, and C. R. Lane. 2004. Floristic quality indices for biotic assessment of depressional marsh condition in Florida. Ecological Applications 14(3):784-794. http://dx.doi. org/10.1890/02-5378

Colding, J., J. Lundberg, S. Lundberg, and E. Andersson. 2009. Golf courses and wetland fauna. Ecological Applications 19 (6):1481-1491. http://dx.doi.org/10.1890/07-2092.1

Conefor. 2014. Applications. http://www.conefor.org/applications. $\underline{\mathrm{html}}$

Costanza, R., M. Wilson, A. Troy, A. Voinov, S. Liu, and J. D' Agostino. 2006. The value of New Jersey's ecosystem services and natural capital. Gund Institute for Ecological Economics, University of Vermont and New Jersey Department of Environmental Protection, Trenton, New Jersey, USA.

Cumming, G. S., D. Cumming, and C. Redman. 2006. Scale mismatches in social-ecological systems: causes, consequences, and solutions. Ecology and Society 11(1):14. [online] URL: http:// www.ecologyandsociety.org/vol11/iss1/art14/

Cumming, G. S., P. Olsson, F. S. Chapin, III, and C. S. Holling. 2013. Resilience, experimentation, and scale mismatches in socialecological landscapes. Landscape Ecology 28(6):1139-1150. http://dx.doi.org/10.1007/s10980-012-9725-4

Cushman, S. A. 2006. Effects of habitat loss and fragmentation on amphibians: a review and prospectus. Biological Conservation 128(2):231-240. http://dx.doi.org/10.1016/j.biocon.2005.09.031

Dale, M. R. T., and M.-J. Fortin. 2010. From graphs to spatial graphs. Annual Review of Ecology, Evolution, and Systematics 41 (1):21-38. http://dx.doi.org/10.1146/annurev-ecolsys-102209-144718

Dekker, D., D. Krackhardt, and T. A. B. Snijders. 2007. Sensitivity of MRQAP tests to collinearity and autocorrelation conditions. Psychometrika 72:563-581. http://dx.doi.org/10.1007/s11336-007-9016-1

Ekstrom, J., and O. Young. 2009. Evaluating functional fit between a set of institutions and an ecosystem. Ecology and Society 14(2):16. [online] URL: http://www.ecologyandsociety. org/vol14/iss2/art16/

Emmelin, L., and P. Lerman. 2006. Styrning av markanvändning och miljö (Governance of land use and the environment). Ansvarskommittén, Stockholm, Sweden.

Ernstson, H., S. Barthel, E. Andersson, and S. Borgström. 2010. Scale-crossing brokers and network governance of urban ecosystem services: the case of Stockholm. Ecology and Society 15(4):28. [online] URL: http://www.ecologyandsociety.org/vol15/ iss $4 / \operatorname{art} 281$

Fahrig, L. 2003. Effects of habitat fragmentation on biodiversity. Annual Review of Ecology, Evolution, and Systematics 34(1):487515. 
Folke, C., T. Hahn, P. Olsson, and J. Norberg. 2005. Adaptive governance of social-ecological systems. Annual Review of Environment and Resources 30(1):441-473. http://dx.doi. org/10.1146/annurev.energy.30.050504.144511

Folke, C., L. Pritchard, F. Berkes, J. Colding, U. Svedin, and L. Pritchard. Jr. 1998. The problem of fit between ecosystems and institutions. IHDP Working Paper No. 2.

Folke, C., L. Pritchard, F. Berkes, J. Colding, and U. Svedin. 2007. The problem of fit between ecosystems and institutions: ten years later. Ecology and Society 12(1):30. [online] URL: http://www. ecologyandsociety.org/vol12/iss1/art30/

Fortuna, M. A., C. Gómez-Rodríguez, and J. Bascompte. 2006. Spatial network structure and amphibian persistence in stochastic environments. Proceedings of the Royal Society B: Biological Sciences 273(1592):1429-1434. http://dx.doi.org/10.1098/rspb.2005.3448

Frost, D. 2013. Amphibian species of the world: an online reference. Version 5.6 (9 January, 2013). American Museum of Natural History, New York, USA. http://dx.doi.org/10.5531/db. vz.0001

Galpern, P., M. Manseau, and A. Fall. 2011. Patch-based graphs of landscape connectivity: a guide to construction, analysis and application for conservation. Biological Conservation 144(1):44 55. http://dx.doi.org/10.1016/j.biocon.2010.09.002

Guerrero, A. M., R. R. J. McAllister, J. Corcoran, and K. A. Wilson. 2013. Scale mismatches, conservation planning, and the value of social network analyses. Conservation Biology 27(1):3544. http://dx.doi.org/10.1111/j.1523-1739.2012.01964.x

Gunnarsson, U., and M. Löfroth. 2009. Våtmarksinventeringen - resultat från 25 års inventeringar (The wetland survey). Swedish Environmental Protection Agency, Stockholm, Sweden.

Haig, S. M., D. W. Mehlman, and L. W. Oring. 1998. Avian movements and wetland connectivity in landscape conservation. Conservation Biology 12(4):749-758.

Hanneman, R., and M. Riddle. 2005. Introduction to social network methods. University of California, Riverside, California, USA. http://faculty.ucr.edu/ hanneman/

Hanski, I. 1999. Metapopulation ecology. Oxford University Press, Oxford.

Hooghe, L., and G. Marks. 2003. Unraveling the Central State, but how? Types of multi-level governance. American Political Science Review 97(2):233-243.

Ingo, S., M. Frithiof, B. Hårsman, and A. Rader Olsson. 2006. Samverkan i Stockholmsregionen (Collaboration in the Stockholm region). In Swedish with English summary.

Joly, P., C. Miaud, A. Lehmann, and O. Grolet. 2001. Habitat matrix effects on pond occupancy in newts. Conservation Biology 15(1):239-248.

Legendre, P., and M.-J. Fortin. 2010. Comparison of the Mantel test and alternative approaches for detecting complex multivariate relationships in the spatial analysis of genetic data. Molecular Ecology Resources 10(5):831-844. http://dx.doi.org/10.1111/ j.1755-0998.2010.02866.x
Lopez, R. D., C. B. Davis, and M. S. Fennessy. 2002. Ecological relationships between landscape change and plant guilds in depressional wetlands. Landscape Ecology 17(1):43-56.

Lopez, R. D., and M. S. Fennessy. 2002. Testing the floristic quality assessment index as an indicator of wetland condition. Ecological Applications 12(2):487-497. http://dx.doi.org/10.1890/1051-0761 (2002)012[0487:TTFQAI]2.0.CO;2

Mantel, N. 1967. The detection of disease clustering and a generalized regression approach. Cancer Research 27(2):209220.

Marsh, D. M., and P. C. Trenham. 2001. Metapopulation dynamics and amphibian conservation. Conservation Biology 15 (1):40-49.

Matthews, J. W., P. A. Tessene, S. M. Wiesbrook, and B. W. Zercher. 2005. Effect of area and isolation on species richness and indices of floristic quality in Illinois, USA wetlands. Wetlands 25 (3):607-615. http://dx.doi.org/10.1672/0277-5212(2005)025[0607: EOAAIO]2.0.CO;2

Niemelä, J., J. H. Breuste, T. Elmqvist, G. Guntenspergen, P. James, and N. E. McIntyre, editors. 2011. Urban ecology: patterns, processes, and applications. Oxford University Press, USA. http:// dx.doi.org/10.1093/acprof:oso/9780199563562.001.0001

Olsson, P., C. Folke, V. Galaz, T. Hahn, and L. Schultz. 2007. Enhancing the fit through adaptive co-management: creating and maintaining bridging functions for matching scales in the Kristianstads Vattenrike Biosphere Reserve, Sweden. Ecology and Society 12(1):28. [online] URL: http://www.ecologyandsociety. org/vol12/iss 1/art28/

Pascual-Hortal, L., and S. Saura. 2006. Comparison and development of new graph-based landscape connectivity indices: towards the priorization of habitat patches and corridors for conservation. Landscape Ecology 21(7):959-967. http://dx.doi. org/10.1007/s10980-006-0013-Z

Pelosi, C., M. Goulard, and G. Balent. 2010. The spatial scale mismatch between ecological processes and agricultural management: Do difficulties come from underlying theoretical frameworks? Agriculture, Ecosystems \& Environment 139(4):455462.

Peterman, W. E., T. A. G. Rittenhouse, J. E. Earl, and R. D. Semlitsch. 2013. Demographic network and multi-season occupancy modeling of Rana sylvatica reveal spatial and temporal patterns of population connectivity and persistence. Landscape Ecology 28(8):1601-1613. http://dx.doi.org/10.1007/ s10980-013-9906-9

Pickett, S. T. A., M. L. Cadenasso, J. M. Grove, C. H. Nilson, R. V. Pouyat, W. C. Zipperer, and R. Costanza. 2001. Urban ecological systems: linking terrestrial ecological, physical, and socioeconomic components of metropolitan areas. Annual Review of Ecology, Evolution, and Systematics 32:127-157. http:// dx.doi.org/10.1146/annurev.ecolsys.32.081501.114012

Pickett, S. T. A., W. B. Burch, Jr., S. E. Dalton, T. W. Foresman, J. Morgan Grove, and R. Rowntree. 1997. A conceptual framework for the study of human ecosystems in urban areas. Urban Ecosystems 1:185-199. http://dx.doi.org/10.1023/A:1018531712889 
Rathwell, K. J., and G. D. Peterson. 2012. Connecting social networks with ecosystem services for watershed governance: a social-ecological network perspective highlights the critical role of bridging organizations. Ecology and Society 17(2):24. http:// dx.doi.org/10.5751/ES-04810-170224

Ray, N., A. Lehmann, and P. Joly. 2002. Modeling spatial distribution of amphibian populations: a GIS approach based on habitat matrix permeability. Biodiversity \& Conservation 11:21432165.

Reiss, K. C. 2006. Florida Wetland Condition Index for depressional forested wetlands. Ecological Indicators 6(2):337352. http://dx.doi.org/10.1016/j.ecolind.2005.03.013

Ribeiro, R., M. A. Carretero, N. Sillero, G. Alarcos, M. OrtizSantaliestra, M. Lizana, and G. A. Llorente. 2011. The pond network: Can structural connectivity reflect on (amphibian) biodiversity patterns? Landscape Ecology 26(5):673-682.

Robins, G., J. M. Lewis, and P. Wang. 2012. Statistical network analysis for analyzing policy networks. Policy Studies Journal 40 (3):375-401. http://dx.doi.org/10.1111/j.1541-0072.2012.00458. $\underline{\mathrm{x}}$

Saura, S., Ö. Bodin, and M.-J. Fortin. 2014. Stepping stones are crucial for species' long-distance dispersal and range expansion through habitat networks. Journal of Applied Ecology 51:171-182. http://dx.doi.org/10.1111/1365-2664.12179

Schmitt, P. 2010. Intra-metropolitan polycentricity in practicereflections, challenges and conclusions from 12 European metropolitan areas. Nordregio, Stockholm, Sweden.

Scott, J. 2000. Social network analysis: a handbook. Sage, London, UK.

Seitzinger, S. P., U. Svedin, C. L. Crumley, W. Steffen, S. A. Abdullah, C. Alfsen, W. J. Broadgate, F. Biermann, N. R. Bondre, J. A. Dearing, L. Deutsch, S. Dhakal, T. Elmqvist, N. Farahbakhshazad, O. Gaffney, H. Haberl, S. Lavorel, C. Mbow, A. J. McMichael, J. M. F. Demorais, P. Olsson, P. F. Pinho, K. C. Seto, P. Sinclair, M. Stafford Smith, and L. Sugar. 2012. Planetary stewardship in an urbanizing world: beyond city limits. Ambio 41 (8):787-794. http://dx.doi.org/10.1007/s13280-012-0353-7

Sjögren, P. 1991. Extinction and isolation gradients in metapopulations: the case of the pool frog (Rana lessonae). Biological Journal of the Linnean Society 42:135-147. http://dx. doi.org/10.1111/j.1095-8312.1991.tb00556.x

Smith, M. A., and D. M. Green. 2005. Dispersal and the metapopulation paradigm in amphibian ecology and conservation: Are all amphibian populations metapopulations? Ecography 28:110-128.

Soomers, H. 2012. Fragmentation and seed dispersal in freshwater wetlands. Utrecht University, Utrecht, The Netherlands.

Steinhardt, U., and M. Volk. 2003. Meso-scale landscape analysis based on landscape balance investigations: problems and hierarchical approaches for their resolution. Ecological Modelling 168(3):251-265.

Stephan, U., S. Langaas, and L. Nordvarg. 2006. Levande vatten (Living waters). Report to Stockholm County Board.
Stockholm County Administrative Board (SCAB). 2013. Våtmarker. http://www.lansstyrelsen.se/stockholm/Sv/miljo-ochklimat/tillstandet-i-miljon/Pages/vatmarker.aspx

Stockholm Municipality. 2007. Metodik för kartläggning av spridningsfunktioner inom Stockholms stad (Methodology for mapping dispersal functions in Stockholm Municipality). Stockholm Municipality, Development Office, Stockholm, Sweden

Sweden. 2010. Plan- och bygglag (Plan and Building Act). SFS 2010:900. Social Ministry, Stockholm, Sweden.

Swedish Environmental Protection Agency (SEPA). 2005. National Strategy for Thriving Wetlands. Stockholm, Sweden.

Swedish Environmental Protection Agency (SEPA). 2012. Sammanställd information om Ekosystemtjänster. 2012. Stockholm, Sweden.

ten Brink P., T. Badura, A. Farmer, and D. Russi. 2012 The economics of ecosystem and biodiversity for water and wetlands. A briefing note. Institute for European Environmental Policy, London, UK and Brussels, Belgium.

Termeer, C., A. Dewulf, and M. Van Lieshout. 2010. Disentangling scale approaches in governance research: comparing monocentric, multilevel, and adaptive governance. Ecology and Society 15(4):29. [online] URL: http://www. ecologyandsociety.org/vol15/iss4/art29/

Tillväxt, miljö och regionplanering (TMR). 2010. Guide to the regional development plan for the Stockholm region - RUFS 2010. Stockholm, Sweden.

Tillväxt, miljö och regionplanering (TMR). 2013. Regionala stadskärnor i Stockholmsregionen (Urban cores in the Stockholm region). Stockholm, Sweden.

Tranvik, L., and U. Bjelke. 2010. Wetlands. Pages 118-123 in U. Gärdenfors, editor. Rödlistade arter i Sverige 2010-The 2010 Red List of Sweden species. ArtDatabanken, SLU, Uppsala, Sweden.

Treml, E. A., Ö. Bodin, P. Fidelman, S. Kininmonth, and J. Ekstrom. 2013. Analysing the (mis)fit between institutional and ecological networks of the coral triangle. Report to the WWFUS Coral Triangle Support Partnership.

Turner, R. K., J. C. J. M. van den Bergh, T. Söderqvist, A. Barendregt, J. van der Straaten, E. Maltby, and E. C. van Ierland. 2000. Ecological-economic analysis of wetlands: scientific integration for management and policy. Ecological Economics 35 (1):7-23. http://dx.doi.org/10.1016/S0921-8009(00)00164-6

Urban, D., and T. Keitt. 2001. Landscape connectivity: a graphtheoretic perspective. Ecology 82(5):1205-1218. http://dx.doi. org/10.2307/2679983

Urban, D. L., E. S. Minor, E. A. Treml, and R. S. Schick. 2009. Graph models of habitat mosaics. Ecology Letters 12(3):260-273. http://dx.doi.org/10.1111/j.1461-0248.2008.01271.x

Vance-Borland, K., and J. Holley. 2011. Conservation stakeholder network mapping, analysis, and weaving. Conservation Letters 4 (4):278-288. http://dx.doi.org/10.1111/j.1755-263X.2011.00176. $\underline{\mathrm{x}}$ 
Wasserman, S., and K. Faust. 1994. Social network analysis: methods and applications. Cambridge University Press.

Wright, C. K. 2010. Spatiotemporal dynamics of prairie wetland networks: power-law scaling and implications for conservation planning. Ecology 91(7):1924-1930. http://dx.doi.org/10.1890/09-0865.1

Young, O. R. 2002. The institutional dimensions of environmental change: fit, interplay, and scale. International environmental agreements: politics, law and economics. Springer.

Zedler, J. B., and S. Kercher. 2005. Wetland resources: status, trends, ecosystem services, and restorability. Annual Review of Environment and Resources 30(1):39-74. http://dx.doi.org/10.1146/ annurev.energy.30.050504.144248

Zetterberg, A., U. M. Mörtberg, and B. Balfors. 2010. Making graph theory operational for landscape ecological assessments, planning, and design. Landscape and Urban Planning 95(4):181191. http://dx.doi.org/10.1016/j.landurbplan.2010.01.002 


\section{Appendix 1}

The wetlands in the national wetland survey.

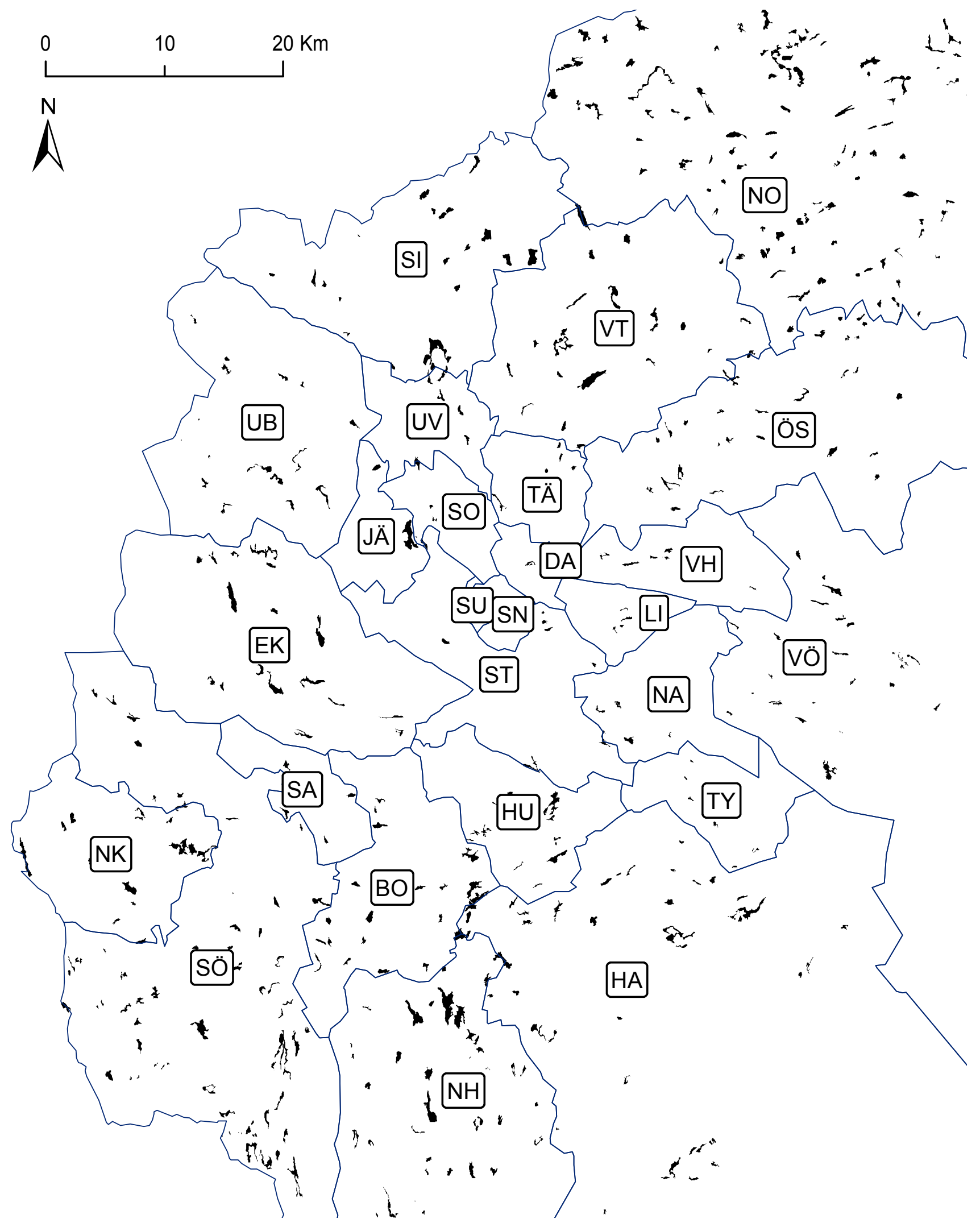




\section{Appendix 2}

We here describe the data of wetlands and dispersal distances that we used to construct the network model of wetland connectivity.

\section{Wetland data}

Our analysis includes all wetlands in Stockholm County present in the National Swedish Wetland Survey (abbr. VMI), which was performed by the county authorities under supervision from the Swedish Environmental Protection Agency (Gunnarsson and Löfroth 2009). It includes 641 wetlands with a mean area of 23.1 ha (22.8 ha standard deviation), in total $148 \mathrm{~km}^{2}$ or $2 \%$ of the county's land area, which is low compared to Sweden in general. The VMI mapped wetlands based on aerial photography and defined wetlands as sites where at least half the vegetation is hydrophilic (including also periodically flooded shores with sparse vegetation). This is similar to the definition of the Ramsar Convention with the exception that areas with permanent water cover, like open lakes and coastal marine areas, are not considered as wetlands in the VMI. The wetlands are divided into four classes relating to conservation values, based on field surveys in around $20 \%$ of the objects, in addition to the aerial photography (SCAB 1997). We include all four classes in our analysis, also the lowest category that holds almost $10 \%$ of the county's wetlands and includes gravely degraded wetland habitats. The classification is however coarse and uncertain, and it is not unambiguously imperative to landscape-ecological planning. For example, local authorities might permit the development of a degraded wetland area with regard to its low conservation values. Alternatively, they might try to restore the degraded wetland if it seem important from a landscape-ecological perspective, for example regarding its location in relation to other wetlands. In addition to restoring the ecological integrity of the specific wetland, such restoration effort could enhance the connectivity of the wetland system.

\section{Wetland connectivity}

The flows of groundwater and surface water are key to the ecological integrity of wetland systems, yet a considerable proportion of the spatial biotic connections in wetland systems are not strongly related to hydrology. Among those are the dispersal processes of fauna over land, and seed dispersal by wind, humans and other animal vectors (Morris 2012; Soomers 2012; Verhoeven et al. 2008). The potential for dispersal depends on the spatial distribution of wetlands - also in the absence of direct hydrological links - and this has implications for landscape planning and conservation (Amezaga et al. 2012). The distances between wetlands condition the chance of dispersal success, which in turn affects the survival of a species and their ability to relocate and recolonize in response to habitat changes and local population dynamics (Bergsten et al. 2013). Connectivity is critical especially to those species whose maximal dispersal distance limits them to colonize only the nearest wetlands, if any (Hanski 1999). More rare, long-distance dispersal events are crucial to population spread and to maintenance of genetic connectivity (Nathan and Muller-Landau 2000). Insufficient long-distance dispersal of native species because of habitat fragmentation is one of the main threats to global biodiversity (Trakhtenbrot et al. 2005). $41 \%$ of the world's amphibian species are threatened (Frost 2013) and the largest potential to halt this decline comes from landscape-scale conservation plans that manage connectivity patterns (Cushman 2006). Amphibians have previously served as indicators of biological diversity in Stockholm Municipality (Löfvenhaft et al. 2004) and their interaction with the landscape make them sensitive to fragmentation (Joly et al. 2001; Sjögren 1991; Vos and Chardon 1998). Their distribution depends largely on juvenile dispersal, yet less studied than adult movement (Edenhamn 1999). Löfvenhaft et al. (2004) suggested amphibian studies as complementary tools for spatial planning in Stockholm, to reveal the impact of land-use changes on spatial and temporal habitat continuity. Spatially explicit population models and network models of 
amphibian populations have both been proven useful to predict and evaluate consequences of land-change scenarios (Ribeiro et al. 2011; Rustigian et al. 2003; Zetterberg et al. 2010).

Sjögren (1991) found a highly elevated risk of local extinction of the pool frog Rana lessonae when inter--wetland distances exceeded $1 \mathrm{~km}$, despite rare dispersal events up to $15 \mathrm{~km}$ (in Austria, Tunner 1969 cited in Sinsch 1990). Reports of the maximum dispersal distance of the common toad Bufo bufo range from 1.6 $\mathrm{km}$ (Sinch 1988) to $1.9 \mathrm{~km}$ in Sweden (Reading et al. 1991) and $3 \mathrm{~km}$ in Switzerland (Heusser 1969 cited in Sinsch 1990). Previous research in Stockholm Municipality has used $2 \mathrm{~km}$ as a maximum spring migration distance for the common toad (Löfvenhaft et al. 2004; Mörtberg et al. 2006). A third amphibian species of conservation interest in Stockholm County is the crested newt Triturus cristatus, for which Halley et al. (1996) used $1 \mathrm{~km}$ as maximum dispersal distance in a population viability study. Recent restorations of wetlands in southern Sweden have improved the situation of previously regionally endangered amphibians (Nyström \& Stenberg 2006; Tranvik \& Bjelke 2010). These include the fire-bellied toad Bombina bombina, the natterjack toad Epidalea calamita and the tree frog Hyla arborea, with respective maximal dispersal distances of $1.7 \mathrm{~km}, 2.6$ $4.4 \mathrm{~km}$ (Smith and Green 2005) and 1.6-12.6km (Edenhamn 1999).

To capture the range of distances outlined above, we here apply 1, 2, 3, 4 and $5 \mathrm{~km}$ as inter-wetland threshold distances to assess connectivity. Using the measure described below we analyze the total connectivity values over the distance range $1-5 \mathrm{~km}$. Unless otherwise clearly stated, the terms "wetland connectivity" or "ecological connectivity" hereafter in this paper refer to inter-wetland connectivity in this distance interval. Our analysis range of $1-5 \mathrm{~km}$ also corresponds to the review of Smith and Green (2005, see figure 3 therein) on dispersal distances of 53 anuran species, where $44 \%$ of 102 references reported maximum movement distances over $1 \mathrm{~km}$, with only some exceptional examples over $8 \mathrm{~km}$. Although specifically selected for amphibians in the region, the $1-5 \mathrm{~km}$ range includes some other processes that connect wetlands. For example, human individuals like bird watchers may walk from one wetland to another within $5 \mathrm{~km}$. There are also non-amphibian species potent to disperse up to maximally 5 kilometers. For example, the common shrew Sorex araneus is found in many biotopes but prefers wet forests and meadows and can disperse maximally up to $5 \mathrm{~km}$ (Tegelström and Hansson 1987). Soomers (2012) studied wind dispersal of the common reed Phragmites australis and found that most seeds were carried shortly $(6 \mathrm{~m}$ medium dispersal) but with some long distance events over $1 \mathrm{~km}$. Many wetland plants depend on assisted dispersal, for which water birds and furry animals are the most significant dispersal vectors (Amezaga et al. 2002; Clausen et al. 2002; Soomers 2012). The movements of wetland birds within and between catchments shape the dispersal pattern of many hydrophilic plants (Amezaga et al. 2002; Figuerola and Green 2002; Haig et al. 1998;). Wichmann (2009) demonstrated that seeds that were dispersed by wind maximally $250 \mathrm{~m}$ were carried by walking humans up to $10 \mathrm{~km}$ (cf. Auffret and Cousins 2013). We stress that our method requires that the interpatch distance be carefully considered when mapping the ecological connections. The precision of network-based connectivity models can be further enhanced by incorporating matrix data, i.e., of the land use between the patches of the focal resource, such as elevation data, the road network or observed dispersal events. 


\section{LITERATURE IN APPENDIX}

Amezaga, J., L. Santamaría, and A. Green. 2002. Biotic wetland connectivity - supporting a new approach for wetland policy. Acta oecologica 23:213-222.

Auffret, A. G., and S. a O. Cousins. 2013. Humans as longdistance dispersers of rural plant communities. PloS one 8(5):e62763.

Bergsten, A., Ö. Bodin, and F. Ecke. 2013. Protected areas in a landscape dominated by logging - A connectivity analysis that integrates varying protection levels with competition- colonization tradeoffs. Biological Conservation 160:279-288.

Clausen, P., B. a. Nolet, a. D. Fox, and M. Klaassen. 2002. Long-distance endozoochorous dispersal of submerged macrophyte seeds by migratory waterbirds in northern Europe - a critical review of possibilities and limitations. Acta Oecologica 23(3):191-203.

Cushman, S. a. 2006. Effects of habitat loss and fragmentation on amphibians: A review and prospectus. Biological Conservation 128(2):231-240.

Edenhamn, P., A. Ekendahl, M. Lönn, and P. Pamilo. 1999. Spridningsförmåga hos svenska växter och djur. Naturvårdsverket, Stockholm.

Figuerola, J., and A. J. Green. 2002. Dispersal of aquatic organisms by waterbirds: a review of past research and priorities for future studies. Freshwater Biology 47(3):483-494.

Gunnarsson, U., and M. Löfroth. 2009.

Våtmarksinventeringen - resultat från 25 års inventeringar (The Wetland Survey). Stockholm.

Haig, S. M., D. W. Mehlman, and L. W. Oring. 1998. Avian Movements and Wetland Connectivity in Landscape Conservation. Conservation Biology 12(4):749-758.

Halley, J., R. Oldham, and J. Arntzen. 1996. Predicting the Persistence of Amphibian Populations with the Help of a Spatial Model. Journal of Applied Ecology 33(3):455470 .

Hanski. 1999. Metapopulation ecology. Oxford Univ. Press, Oxford.

Joly, P., C. Miaud, A. Lehmann, and O. Grolet. 2001. Habitat matrix effects on pond occupancyin newts. Conservation Biology 15(1):239-248.

Löfvenhaft, K. 2004. Biotope patterns and amphibian distribution as assessment tools in urban landscape planning. Landscape and Urban Planning 68:403-427.

Morris, K. 2012. Wetland connectivity: understanding the dispersal of organisms that occur in Victoria 's wetlands. Heidelberg,Victoria.
Mörtberg, U., A. Zetterberg, and M. Gontier. 2006. Landskapsekologisk analys för miljöbedömning: Metodutveckling med groddjur som exempel. Stockholm Municipality, Stockholm.

Nathan, R., and H. Muller-Landau. 2000. Spatial patterns of seed dispersal, their determinants and consequences for recruitment. Trends in ecology \& evolution 15(7):278285 .

Nyström, P., and M. Stenberg. 2006. Utvärdering av åtgärdsprogram för bevarande av lövgroda (Hyla arborea). Skåne County Council.

Reading, C., J. Loman, and T. Madsen. 1991 . Breeding pond fidelity in the common toad, Bufo bufo. Journal of Zoology 225:201-211.

Ribeiro, R., M. a. Carretero, N. Sillero, G. Alarcos, M. Ortiz--Santaliestra, M. Lizana, and G. a. Llorente. 2011. The pond network: can structural connectivity reflect on (amphibian) biodiversity patterns? Landscape Ecology 26(5):673-682.

Rustigian, H., M. Santelmann, and N. Schumaker. 2003. Assessing the potential impacts of alternative landscape designs on amphibian population dynamics. Landscape Ecology:65-81.

SCAB (Stockholm County Administrative Board). 1997. Våtmarksinventering i Stockholms län. (Wetland Survey in Stockholm County). Stockholm.

Sinsch, U. 1988. Seasonal changes in the migratory behaviour of the toad Bufo bulb: direction and magnitude of movements. Oecologia 76:390-398.

Sinsch, U. 1990. Migration and orientation in anuran amphibians. Ethology Ecology \& Evolution 2:37-41.

Sjögren, P. 1991. Extinction and isolation gradients in metapopulations: the case of the pool frog (Rana lessonae). Biological Journal of the Linnean society 42:135-147.

Smith, M., and D. Green. 2005. Dispersal and the metapopulation paradigm in amphibian ecology and conservation: are all amphibian populations metapopulations? Ecography 28:110- 128.

Soomers, H. 2012. Fragmentation and seed dispersal in freshwater wetlands. Utrecht University.

Tegelström, H., and L. Hansson. 1987. Evidence of long distance dispersal in the common shrew (Sorex araneus). International journal of mammalian biology 52:52-54.

Trakhtenbrot, A., R. Nathan, G. Perry, and D. M. Richardson. 2005. The importance of long-distance dispersal in biodiversity conservation. Diversity and Distributions 11(2):173-181. 
Tranvik, L., and U. Bjelke. 2010. Wetlands. Pages 118-123 in U. Gärdenfors, editor. Rödlistade arter i Sverige 2010The 2010 Red List of Sweden Species. ArtDatabanken, SLU, Uppsala.

Verhoeven, J. T. a., M. B. Soons, R. Janssen, and N. Omtzigt. 2008. An Operational Landscape Unit approach for identifying key landscape connections in wetland restoration. Journal of Applied Ecology 45(5):1496-1503.

Vos, C., and J. Chardon. 1998. Effects of habitat fragmentation and road density on the distribution pattern of the moor frog Rana arvalis. Journal of Applied Ecology 35(1):44-56.

Wichmann, M. C., M. J. Alexander, M. B. Soons, S. Galsworthy, L. Dunne, R. Gould, C. Fairfax, M.

Niggemann, R. S. Hails, and J. M. Bullock. 2009. Humanmediated dispersal of seeds over long distances.

Proceedings. Biological sciences / The Royal Society 276(1656):523-32.

Zetterberg, A., U. M. Mörtberg, and B. Balfors. 2010. Making graph theory operational for landscape ecological assessments, planning, and design. Landscape and Urban Planning 95(4):181-191. 


\section{Appendix 3}

Characteristics of the surveyed municipalities. The abbreviations are used in the figures in the manuscript. Outdegree is the number of (outgoing) links reported by the municipality on the same row. Indegree is the number of (ingoing) links that other municipalities reported. Betweenness centrality represents how many times the municipality occur in shortest network paths between other municipalities (that are not directly connected with each other).

\begin{tabular}{|c|c|c|c|c|c|c|}
\hline Municipality & $\begin{array}{l}\text { Abbre- } \\
\text { viation }\end{array}$ & $\begin{array}{r}\text { Out- } \\
\text { degree }\end{array}$ & $\begin{array}{r}\text { In- } \\
\text { degree }\end{array}$ & $\begin{array}{l}\text { Betwe- } \\
\text { enness }\end{array}$ & $\begin{array}{r}\text { Respond- } \\
\text { ents }\end{array}$ & $\begin{array}{r}\text { Population } \\
(* 1000)\end{array}$ \\
\hline Botkyrka & $\mathrm{BO}$ & 8 & 5 & 15 & 1 & 87 \\
\hline Danderyd & DA & 4 & 5 & 0 & 1 & 32 \\
\hline Ekerö & EK & 7 & 1 & 0 & 1 & 26 \\
\hline Haninge & HA & 9 & 5 & 15 & 1 & 81 \\
\hline Huddinge & HU & 2 & 6 & 0 & 1 & 102 \\
\hline Järfälla & JÄ & 0 & 5 & 0 & 1 & 69 \\
\hline Lidingö & LI & 0 & 1 & 0 & 1 & 45 \\
\hline Nacka & NA & 2 & 1 & 0 & 2 & 94 \\
\hline Norrtälje & $\mathrm{NO}$ & 3 & 3 & 0 & 1 & 57 \\
\hline Nykvarn & NK & 8 & 4 & 0 & 1 & 10 \\
\hline Nynäshamn & $\mathrm{NH}$ & 0 & 6 & 0 & 1 & 27 \\
\hline Salem & SA & 0 & 5 & 0 & 1 & 16 \\
\hline Sigtuna & SI & 1 & 6 & 0 & 1 & 43 \\
\hline Sollentuna & SO & 9 & 6 & 51 & 1 & 68 \\
\hline Solna & $\mathrm{SN}$ & 4 & 4 & 3 & 1 & 73 \\
\hline Stockholm & ST & 19 & 9 & 77 & 2 & 896 \\
\hline Sundbyberg & SU & 5 & 4 & 3 & 1 & 42 \\
\hline Södertälje & SÖ & 8 & 4 & 0 & 1 & 91 \\
\hline Tyresö & TY & 1 & 7 & 0 & 1 & 44 \\
\hline Täby & $\mathrm{T} \ddot{\mathrm{A}}$ & 4 & 3 & 28 & 2 & 66 \\
\hline Upplands Väsby & UV & 0 & 4 & 0 & 1 & 41 \\
\hline Upplands-Bro & UB & 0 & 1 & 0 & 1 & 25 \\
\hline Vallentuna & VT & 4 & 4 & 39 & 1 & 32 \\
\hline Vaxholm & VH & 0 & 2 & 0 & 1 & 11 \\
\hline Värmdö & VÖ & 0 & 1 & 0 & 1 & 40 \\
\hline Österåker & ÖS & 6 & 2 & 15 & 1 & 40 \\
\hline
\end{tabular}




\section{Appendix 4}

Below we present the web survey that we used to map inter-municipal collaborations. This version is converted to English from the Swedish web version. Space to fill in answers is marked by “_”.

\section{Part 1 - Your job and your experience}

1.1 Your current position

What is you current post at municipality $\mathrm{X}$ ?

\subsection{Experience in municipality $\mathrm{X}$}

For how long have you worked in municipality $\mathrm{X}$ ?

- years

\subsection{Experience in other municipalities}

Have you worked in other municipalities? If yes, please state the name of the municipality, what was your job there, and for how long

\subsection{Relation to decision making}

How much are you involved in the process of green-area and land-use planning (multiple answers allowed)

_ Not involved

_ Data gathering, knowledge basis (author or reports, compiling collected data)

_ Counseling (direct counseling to decision makers through regular meetings)

_ Directly involved (makes decisions)

1.5 Colleagues in conservation and green-area issues

Please estimate the number of people in the municipal administration that mainly work with conservation and green-area planning (e.g., management, monitoring, inventories, investigation, planning, etc.)

_ persons, including myself

1.6 Other comments

You may here provide more information about your role/position in green-area and land-use planning

\section{Part 2 - Inter-municipal collaborations}

We ask you to report collaborations that your municipality has with other municipalities in Stockholm County, and which you know about or participate in. The collaborations can be informal or formal, like a joint project about water management, a nature reserve or a green wedge. 
2.1

For each of the municipal councils in column 1, please mark the focal type of ecosystem resource (in column 2: "Collaboration - resource type"). The types are forested land ("Forest"), constructed parks ("Park"), wetlands and streams ("Wetlands"), or another resource type ("other"). Use the comments fields ("Comm.") for a resource type to further specify what type of resource the collaboration is targeting.

For each collaboration tie, please select on of the following "levels" of collaboration.

- No collaboration related to this resource type ("None")

- Exchange of ready-made reports ("Exchange", exchange of information about the resource)

- Coauthoring of reports ("Coauthor", joint collection and/or compilation of data, joint processing and authoring of reports about the resource)

- Joint planning or decision making ("Joint", decisions about the resource are discussed, negotiated and synchronized with the partner)

We also ask you (in column 3) to refer to your colleagues in the municipal administration who work with these inter-municipal collaborations (your answer is confidential and we use it only to identify relevant respondents to this survey). Finally, use column 4 to provide further information or comments.

Below is an example of how an answer may look like.

\begin{tabular}{|c|c|c|c|c|c|c|c|}
\hline 1. Municipality & & 2. Collabor & $n-r e$ & urce type & & 3. Colleagues & 4. Comments \\
\hline \multirow{6}{*}{ Stockholm } & & Forest & $\underline{\text { Park }}$ & Wetland & Other & \multirow{6}{*}{$\begin{array}{l}\text { Lisa Nilsson, } \\
\text { Bertil Karlsson }\end{array}$} & \\
\hline & None & $\checkmark$ & & $\checkmark$ & & & \\
\hline & Exchange & & & & $\checkmark$ & & \\
\hline & Coauthor & & & & & & \\
\hline & Joint & & $\checkmark$ & & & & \\
\hline & Comment & & & & & & \\
\hline \multirow{6}{*}{ Botkyrka } & & Forest & Park & Wetland & Other & & \multirow{6}{*}{$\begin{array}{l}\text { We exchange } \\
\text { biodiversity } \\
\text { information } \\
\text { about birds }\end{array}$} \\
\hline & None & & & & & & \\
\hline & Exchange & $\checkmark$ & $\checkmark$ & $\checkmark$ & & & \\
\hline & Coauthor & & & & & & \\
\hline & Joint & & & & & & \\
\hline & Comment & & & & & & \\
\hline
\end{tabular}

[A full table with all 26 municipalities then followed, for the respondent to fill in.]

\subsection{Your participation}

What is the total time that you spend on maintaining these collaborations, per month?

- hours 